\title{
O IDEB COMO INDICADOR DA QUALIDADE DA EDUCAÇÃO BRASILEIRA: O CASO DA REGIÃO SUDESTE
}

\section{IDEB AS AN INDICATIVE OF THE QUALITY OF BRAZILIAN EDUCATION: THE SOUTH EAST REGION CASE}

\author{
Cláudia Cristina Rios Caxias da Costa
}

\author{
Programa de Pós-Graduação em Geografia - Tratamento da Informação Espacial da PUC \\ Minas, Belo Horizonte, MG \\ riosdacosta@terra.com.br
}

\begin{abstract}
Resumo - O Índice de Desenvolvimento da Educação Básica (IDEB) é um indicador que combina informações de fluxo e de desempenho dos alunos, criado para promover um sistema de responsabilidade ${ }^{l}$, visando à melhoria da qualidade da educação no país. Ao elaborar metas detalhadas para cada rede de ensino e escola com as quais governadores e prefeitos se comprometeram por meio do Compromisso Todos Pela Educação, ao calcular e divulgar amplamente os resultados do Ideb, o Instituto Nacional de Estudos e Pesquisas Educacionais Anísio Teixeira (INEP) possibilitou que os atores educacionais pudessem ser responsabilizados pelos resultados de sua unidade e que o Ministério da Educação (MEC) identificasse e premiasse as escolas que atingem as metas, mas também oferecesse assistência técnica e financeira para as redes com piores resultados. Neste artigo, serão tratadas a origem, princípios e matrizes teóricometodológicas do Ideb, com base, sobremaneira, nas notas técnicas disponibilizadas pelo Inep, desde a concepção deste indice, em 2007. Para denotar a importância do indice, utilizar-se-ão dados dos anos 2005, 2007 e 2009 e projeções referentes às unidades federativas que compõem a Região Sudeste brasileira.
\end{abstract}

\footnotetext{
${ }^{1}$ Aqui colocada como tradução literal do vernáculo inglês accountability, designando a obrigação dos agentes públicos em responder por suas decisões, ações e omissões, procedimento universalmente consagrado como norma nas sociedades mais desenvolvidas.
}

Palavras-chave - Educação, Desempenho escolar, IDEB, Região Sudeste.

Abstract - The "Índice de Desenvolvimento da Educação Básica -IDEB" (Development of Basic Education index) is an indicator which combines information relating to student flows and performance levels, created to promote a system of accountability [1] aiming to increase the quality of education in the country. When organizing detailed goals for each school network- which governors and mayors are engaged with by means of the program "Compromisso Todos Pela Educação"when calculating and distributing widely the results of IDEB, the "Instituto Nacional de Estudos e Pesquisas Educacionais Anisio Teixeira - INEP" provided that the educational parties could be held responsible for the results of their institution and the "Ministério da Educação- MEC" (Department of Education) identifies and awards a prize to the schools which have achieved their goals, and also offers technical and financial aid to those that have obtained the worst results. In this paper,the origin, principles and theoretical methodology matrix of IDEB will be dealt with, based on the technical scores provided by INEP, since the conception of this index in 2007.To denote the importance of the index, it will utilize data from the years of 2005,2007 and 2009 and the projections relating to the Federative Units that compose the South East region of Brazil.

Keywords - Education, School performance, IDEB, South East region.

\begin{tabular}{|l|l|l|l|}
\hline Con & ISSN: 1984-3151 & www.unibh.br/revistas/exacta/ & Vol. 3 N. ${ }^{\text {2 }}$ (2010) \\
\hline
\end{tabular}




\section{INTRODUÇÃO}

No Brasil, a importância de uma educação de excelência perpassa a concepção de programas e mecanismos que objetivem a melhoria, bem como o monitoramento da qualidade de ensino vigente no país. Assim, em 2007, foi criado o Plano de Desenvolvimento da Educação (PDE), cujo principal foco é avaliar a situação de cada município brasileiro e suas instituições escolares, através do Índice de Desenvolvimento da Educação Básica (IDEB).

Constituindo-se no principal indicador de qualidade da educação básica no Brasil na atualidade, o Ideb ${ }^{2}$, é aferido e divulgado pelo Ministério da Educação (MEC) através do Instituto Nacional de Estudos e Pesquisas Educacionais Anísio Teixeira (INEP) a cada dois anos. O INEP é uma autarquia federal vinculada ao MEC, concebida com o propósito de promover estudos, pesquisas e avaliações sobre o Sistema Educacional Brasileiro, objetivando subsidiar a formulação e implementação de políticas públicas para a área educacional a partir de parâmetros de qualidade e equidade. É também, meta do INEP, produzir e disponibilizar informações claras e confiáveis aos gestores, pesquisadores, educadores e público em geral.

O Ideb combina informações de desempenho em exames padronizados (Prova Brasil ou Saeb), obtido pelos estudantes ao final das etapas de ensino $\left(4^{\mathrm{a}}\right.$ e $8^{\mathrm{a}}$ séries do ensino fundamental ${ }^{3}$ e $3^{\mathrm{a}}$ série do ensino médio), com informações sobre rendimento escolar (taxa média de

\footnotetext{
${ }^{2}$ Por uma questão de estilo, esta sigla, ao longo do artigo, será escrita na forma Ideb. O mesmo procedimento para as siglas Saeb e Inep.

${ }^{3}$ Para o Ensino Fundamental composto por nove anos, estas séries correspondem ao $5^{\circ}$ e $9^{\circ}$ anos, respectivamente.
}

aprovação) $)^{4}$. Considera-se raro que estudos e análises sobre qualidade educacional combinem as informações produzidas por esses dois tipos de indicadores, ainda que a complementaridade entre elas seja evidente.

A Prova Brasil avalia todos os estudantes das escolas públicas urbanas com mais de 20 alunos por série, em relação a seus conhecimentos de Língua Portuguesa e Matemática. Os resultados obtidos fornecem médias de desempenho para os municípios brasileiros, assim como para os Estados, Regiões e também o país como um todo. O Saeb é um exame bienal, aplicado em escolas urbanas pertencentes às redes pública e privada, tratando-se de uma avaliação amostral, e assim sendo, os resultados obtidos se referem ao Brasil, às suas regiões administrativas e unidades federativas. Os alunos são avaliados na $4^{\mathrm{a}} \mathrm{e}$ $8^{\mathrm{a}}$ Série $\left(5^{\circ}\right.$ e $9^{\circ}$ anos $)$ do Ensino Fundamental e no $3^{\circ}$ ano do Ensino Médio em relação a seus conhecimentos de Língua Portuguesa e de Matemática (foco na leitura e resolução de problemas, respectivamente).

Desta forma, o Ideb pode ser compreendido como uma fotografia do desempenho dos estudantes do ensino fundamental e do ensino médio. As redes públicas da educação básica que já alcançaram o Ideb acima de seis pontos igualaram-se aos índices dos países mais desenvolvidos e industrializados do mundo, segundo a Organização para a Cooperação e Desenvolvimento Econômico (OCDE). A meta do MEC é

\footnotetext{
${ }^{4} \mathrm{Nas}$ médias do Ideb, estão ponderados estatisticamente os dados sobre aprovação escolar, oriundos dos Censos Escolares e as médias no Sistema de Avaliação da Educação Básica (Saeb), no caso dos estados e do País, e na Prova Brasil, aplicada entre os municípios. $O$ índice tem a capacidade, então, de mostrar se uma escola ou rede aprova o aluno sem que ele de fato aprenda ou se ele reprova para tentar melhorar as próprias notas apenas.
} 
que todas as redes alcancem a nota seis em 2022, ano do bicentenário da independência do Brasil.

Não é aceitável que um sistema educacional reprove sistematicamente seus alunos, fazendo com que grande parte deles abandone a escola antes de completar a educação básica, mesmo que os concluintes dessa etapa de ensino atinjam elevadas pontuações nos exames padronizados. Entretanto, um sistema em que todos os alunos concluem o ensino médio no período correto, também não é interessante, caso os alunos aprendam muito pouco na escola. Em resumo, um sistema de ensino ideal (grifo da autora) seria aquele em que todas as crianças e adolescentes tivessem acesso à escola, não desperdiçassem tempo com repetências, não abandonassem a escola precocemente e, ao concluírem, aprendessem os conteúdos propostos.

No Brasil é notório que a questão do acesso à escola não é mais um problema, já que quase a totalidade das crianças em idade escolar ingressa no sistema educacional. Entretanto, as taxas de repetência dos alunos são bastante elevadas, assim como a proporção de adolescentes que abandonam a escola antes mesmo de concluir a educação básica. Outro indicador preocupante é a baixa proficiência obtida pelos alunos em exames padronizados.

Uma forma simples de compreender este índice é entendê-lo como resultado do produto entre o desempenho e rendimento escolar, ou ainda como o inverso do tempo médio de conclusão de uma determinada série.

Exemplificando: para uma escola A, cuja média padronizada da Prova Brasil para a $4^{\mathrm{a}}$ série, é 5,0 e o tempo médio de conclusão de cada série é de dois anos, a rede de ensino ou escola terá o Ideb igual a 5,0 que multiplicado por $1 / 2$, resultará no
Ideb igual a 2,5. Já para uma escola $\mathbf{B}$ com média padronizada da Prova Brasil, para a $4^{\mathrm{a}}$ série, igual a 5,0 e tempo médio para conclusão igual a um ano, será obtido o Ideb de valor 5,0.

\section{EDUCAÇÃO E DESIGUALDADES REGIONAIS}

É notório que a Região Sudeste, principalmente pela pujança econômica e qualidade de vida de sua população, se destaca em relação às demais regiões brasileiras. As tabelas 1 e 2, a seguir, mostram a população e o produto interno bruto (PIB) dos estados que a compõem.

Tabela 1 - População residente na Região Sudeste, por unidade federativa em 2007

\begin{tabular}{l|c}
\hline Região Sudeste & $\mathbf{7 7 . 8 7 3 . 1 2 0}$ \\
\hline Minas Gerais & 19.273 .506 \\
Espírito Santo & 3.351 .669 \\
Rio de Janeiro & 15.420 .375 \\
São Paulo & 39.827 .570 \\
\hline Fonte: IBGE, 2007.
\end{tabular}

Tabela 2 - Produto Interno Bruto para a Região Sudeste, por unidade federativa, 2007

\begin{tabular}{l|c}
\hline Região Sudeste & R\$ 1.501.184.922,00 \\
\hline Minas Gerais & $\mathrm{R} \$ 241.293 .053,70$ \\
Espírito Santo & $\mathrm{R} \$ 60.339 .817,27$ \\
Rio de Janeiro & $\mathrm{R} \$ 296.767 .783,80$ \\
São Paulo & $\mathrm{R} \$ 902.784 .267,70$ \\
\hline Fonte: IBGE, 2007.
\end{tabular}

A Região Sudeste tem o maior número de municípios, entre as cinco regiões do país, com os mais altos índices de desenvolvimento da educação básica registrados em suas três edições. Dados do MEC denotaram que em 2007, por exemplo, as redes municipais da região tiveram 38 dos 51 municípios do país com Ideb acima de 6 pontos na quarta série do ensino fundamental e 35 municípios com índice acima de 5 pontos na oitava série do ensino fundamental. A pontuação mostrou que esse grupo de municípios superou as metas projetadas pelo Ministério da Educação para 2007, 2009 e 2011.

\begin{tabular}{|l|l|l|l|}
\hline Con & ISSN: 1984-3151 & www.unibh.br/revistas/exacta/ & Vol. 3 N. ${ }^{\text {o }} 2$ (2010) \\
\hline
\end{tabular}


Em contrapartida, em 2009, os dados do Ideb confirmaram as extremas desigualdades regionais existentes no Brasil. Dos 325 municípios com nota igual ou superior a seis, $317(97,5 \%)$ estão nas regiões sul e sudeste, mais precisamente concentrados nos estados de Minas Gerais (121 municípios), São Paulo (123 municípios) e Paraná (35 municípios). As unidades federativas de Santa Catarina (19 municípios), Rio Grande do Sul (14 municípios), Espírito Santo (4 municípios) e Rio de Janeiro (1 município) complementam o panorama de supremacia no campo educacional brasileiro ${ }^{5}$.

Um montante de 276 municípios, em 2009, obteve notas iguais ou inferiores a três, assim distribuídos entre as unidades federativas brasileiras: Acre (1 município), Roraima (1 município), Amazonas (9 municípios), Amapá (3 municípios), Pará (24 municípios), Mato Grosso(1 município), Minas Gerais (2 municípios) e Rio Grande do Sul (1 município). A Região Nordeste, contrastando com a Região Sudeste, apresentou 234 municípios com Ideb inferior ou igual a três, a saber: Bahia (55 municípios), Piauí (47 municípios), Rio Grande do Norte (40 municípios), Maranhão (23 municípios), Paraíba (22 municípios), Sergipe (20 municípios), Alagoas (14 municípios), Pernambuco (12 municípios) e Ceará (1 município).

De acordo com Fernandes (2007), o Brasil ainda trilha um longo caminho, no que tange ao aumento das taxas de aprovação em cada série escolar,

5 O Instituto Nacional de Estudos e Pesquisas Educacionais Anísio Teixeira (INEP) apontou, também, para 2009, seis municípios na Região Centro-Oeste (três do Estado de Goiás e três do Mato Grosso) e dois municípios na Região Nordeste (Sobral e Abaiara, ambos no Ceará) com Ideb igual ou superior a seis. A Região Norte não apresentou nenhum município com Ideb na faixa estabelecida pelo MEC. diminuição do número de crianças que abandonam a escola e melhorias na qualidade do seu sistema educacional. Apesar dos avanços observados a cada dois anos, desde 2005, o país ainda está bem distante da meta proposta pelo PDE: a nota seis. A média do país em 2009 foi de 4,6 nas primeiras séries do ensino fundamental, 4,0 nas séries finais para uma projeção de 5,5 em 2021 e 3,6 no ensino médio para uma média projetada em 2021 de 5,2 .

\section{MATRIZES METODOLÓGICAS PARA O CÁlCUlO DO IDEB}

Indicadores educacionais, a exemplo do Ideb, são desejáveis por permitirem o monitoramento do sistema de ensino nacional. Sua importância, em termos de diagnóstico e norteamento de ações políticas focalizadas na melhoria do sistema educacional, está em:

- detectar escolas e/ou redes de ensino cujos alunos apresentem baixa performance em termos de rendimento e proficiência;

- monitorar a evolução temporal do desempenho dos alunos dessas escolas e/ou redes de ensino ${ }^{6}$.

\section{III.1 VARIÁVEIS CONTEMPLADAS E AGREGAÇÕES PARA O CÁLCULO DO IDEB}

Os resultados do Ideb para a Região Sudeste brasileira foram calculados a partir do desempenho obtido pelos alunos que participaram da Prova Brasil/Saeb, nos anos de 2005, 2007 e 2009 e das taxas de

\footnotetext{
${ }^{6}$ As autoridades educacionais podem, por exemplo, financiar programas para promover o desenvolvimento educacional de redes de ensino em que os alunos apresentam baixo desempenho. Assim, monitorar as redes financiadas, para verificar se elas apresentam uma melhora de desempenho, é fundamental. Aliás, o financiador poderia estipular previamente o avanço desejado no indicador como contrapartida para a liberação de recursos.
} 
aprovação, calculadas com base nas informações prestadas no Censo Escolar (2007 e 2009, corroborando com o biênio de realização do Ideb). Assim, cada uma destas unidades de agregação tem seu próprio Ideb e metas estabelecidas ao longo do horizonte do PDE, ou seja, até 2021.

Neste estudo, o Ideb para 2005, 2007 e 2009, contemplou as seguintes unidades de agregação, em função das características metodológicas da Prova Brasil/Saeb:

Ensino Fundamental - Anos Iniciais

Unidades da Federação: Minas Gerais, São Paulo, Espírito Santo e Rio de Janeiro

- Total (Escolas públicas urbanas e escolas privadas urbanas);

- Rede Estadual (Escolas urbanas da rede estadual);

- Rede Privada (Escolas urbanas da rede privada).

Ensino Fundamental - Séries Finais

Unidades da Federação: Minas Gerais, São Paulo, Espírito Santo e Rio de Janeiro

- Total (Escolas públicas urbanas e escolas privadas urbanas);

- Rede Estadual (Escolas urbanas da rede estadual);

- Rede Privada (Escolas urbanas da rede privada).

\section{Ensino Médio ${ }^{7}$}

Unidades da Federação: Minas Gerais, São Paulo, Espírito Santo e Rio de Janeiro

- Total (Escolas públicas urbanas e escolas privadas urbanas);

- Rede Estadual (Escolas urbanas da rede estadual);

- Rede Privada (Escolas urbanas da rede privada).

\footnotetext{
${ }^{7}$ Para o Ensino Médio, o Ideb só pode ser calculado para unidades federativas, regiões e Brasil, ao contrário do Ensino Fundamental, que contempla, também, municípios brasileiros e suas instituições escolares.
}

\section{III.2 FORMULAÇÕES PARA O CÁLCULO DO IDEB}

A evidente complementaridade entre indicadores de fluxo e pontuações em exames padronizados obtidas por alunos ao final de determinada etapa do sistema de ensino $\left(4^{\mathrm{a}}\right.$ e $8^{\mathrm{a}}$ séries do ensino fundamental - ou $5^{\circ}$ e $9^{\circ}$ anos, respectivamente - e $3^{\circ}$ ano do ensino médio), permite que o Ideb considere como resultado a combinação de dois outros indicadores:

a) pontuação média dos estudantes em exames padronizados ao final de determinada etapa da educação básica $\left(4^{\mathrm{a}}\right.$ e $8^{\mathrm{a}}$ séries do ensino fundamental e $3^{\circ}$ ano do ensino médio) e;

b) taxa média de aprovação dos estudantes da correspondente etapa de ensino.

De acordo com Fernandes (2007), a proposta de concepção do Ideb é de que ele seja de fácil compreensão, simples de calcular, aplicável às escolas e explícito em relação à "taxa de troca" entre probabilidade de aprovação e proficiência dos estudantes. Em outras palavras, o indicador torna claro o quanto se está disposto a perder na pontuação média do teste padronizado para se obter determinado aumento na taxa média de aprovação. Diante dessa proposta, Alves (2007) ressalta que o Ideb não segue o caminho metodológico de transformar os resultados do SAEB de série para uma determinada geração. Assim, a forma geral do Ideb é dada por (1):

$$
\begin{aligned}
& I D E B_{j i}=N_{j i} P_{j i} ; \\
& 0 \leq N_{j} \leq 10 ; 0 \leq P_{j} \leq 1 e \\
& 0 \leq I D E B_{j} \leq 10
\end{aligned}
$$

Onde:

$i=$ ano do exame (Saeb e Prova Brasil) e do Censo Escolar; 
$N_{j i}=$ média da proficiência em Língua Portuguesa e Matemática, padronizada para um indicador entre 0 e 10 , dos alunos da unidade $j$, obtida em determinada edição do exame realizado ao final da etapa de ensino;

$P_{j i}=$ indicador de rendimento baseado na taxa de aprovação da etapa de ensino dos alunos da unidade $\mathrm{j}$;

Em (1), a média de proficiência padronizada dos estudantes da unidade $j$, $N_{j i}$, é obtida a partir das proficiências médias em Língua Portuguesa e Matemática dos estudantes submetidos a determinada edição do exame realizado ao final da etapa educacional considerada (Prova Brasil ou Saeb). A proficiência média é padronizada para estar entre zero e dez, de modo que $0 \leq \mathrm{IDEB} \leq 10 . N_{j i}$ é obtida de acordo com (2).

$$
\begin{aligned}
& N_{j i}=\frac{\eta_{j i}^{l p}+\eta_{j i}^{\text {mat }}}{2} e \\
& \eta_{j i}^{\alpha}=\frac{S_{j i}^{\alpha}-S_{\text {inf }}^{\alpha}}{S_{\text {sup }}^{\alpha}-S_{\text {inf }}^{\alpha}} * 10
\end{aligned}
$$

Onde:

$\eta_{j i}^{\alpha}=$ proficiência na disciplina $\alpha$, obtida pela unidade $j$, no ano $i$, padronizada para valores entre 0 e 10 ;

$\alpha=$ disciplina (Matemática ou Língua Portuguesa);

$S_{j i}^{\alpha}=$ proficiência média (em Língua

Portuguesa ou Matemática), não padronizada, dos alunos da unidade $j$ obtida no exame do ano $i$;

$S_{\text {inf }}^{\alpha}=$ limite inferior da média de proficiência (Língua Portuguesa ou Matemática) do Saeb 1997;

$S_{\text {sup }}^{\alpha}=$ limite superior da média de proficiência (Língua Portuguesa ou Matemática) do Saeb 1997.
Para as unidades escolares, ou redes de ensino, que obtiverem $S_{j i}^{\alpha}<S_{\text {inf }}^{\alpha}$, a proficiência média é fixada em $S_{\text {inf }}^{\alpha}$. Por sua vez, aquelas unidades que obtiverem $S_{j i}^{\alpha}>S_{\text {sup }}^{\alpha}$ têm o desempenho fixado em $S_{\text {sup }}^{\alpha}$. A Tabela 3 apresenta a média e o desvio padrão das proficiências dos alunos da $4^{\mathrm{a}}$ e da $8^{\mathrm{a}}$ série do ensino fundamental e da $3^{\text {a }}$ série do ensino médio no Saeb de 1997, ano em que a escala do Saeb foi definida. Posteriormente, a Tabela 4 traz os valores dos limites inferiores e superiores utilizados na padronização das proficiências médias em Língua Portuguesa e Matemática dos alunos da $4^{\mathrm{a}}$ e da $8^{\text {a }}$ série do ensino fundamental e da $3^{\mathrm{a}}$ série do ensino médio.

Tabela 3 - Saeb 1997: Proficiências médias e desvio padrão

\begin{tabular}{c|c|c|c|c}
\hline \multirow{2}{*}{ Série } & \multicolumn{2}{|c|}{ Matemática } & \multicolumn{2}{c}{$\begin{array}{c}\text { Língua } \\
\text { Portuguesa }\end{array}$} \\
\cline { 2 - 5 } & Média & $\begin{array}{c}\text { Desvio } \\
\text { Padrão }\end{array}$ & Média & $\begin{array}{c}\text { Desvio } \\
\text { Padrão }\end{array}$ \\
\hline $\begin{array}{c}4^{\mathrm{a}} \text { do } \\
\text { EF }\end{array}$ & 190.8 & 44 & 186.5 & 46 \\
\hline $\begin{array}{c}8^{\mathrm{a}} \text { do } \\
\text { EF }\end{array}$ & 250.0 & 50 & 250.0 & 50 \\
\hline $\begin{array}{c}3^{\mathrm{a}} \text { do } \\
\text { EM }\end{array}$ & 288.7 & 59 & 283.9 & 56 \\
\hline
\end{tabular}

Fonte: Saeb/Inep/Mec, 1997

A partir da média e desvio padrão $(D P)$ das proficiências no Saeb 1997, foi calculado, para cada etapa de ensino, considerando as diferentes disciplinas avaliadas no exame, o limite inferior e superior, de acordo com:

$$
S_{\mathrm{inf}}^{\alpha}=m e ́ d i a_{\alpha}-(3 * D P) \text { e } S_{\text {sup }}^{\alpha}=m e ́ d i a_{\alpha}+
$$$$
(3 * D P) \text {. }
$$ 
Tabela 4 - Limite superior e inferior das proficiências

\begin{tabular}{c|c|c|c|c}
\hline \multirow{2}{*}{ Série } & \multicolumn{2}{|c|}{ Matemática } & \multicolumn{2}{c}{$\begin{array}{c}\text { Língua } \\
\text { Portuguesa }\end{array}$} \\
\cline { 2 - 5 } & $S_{\text {inf }}$ & $S_{\text {sup }}$ & $S_{\text {inf }}$ & $S_{\text {sup }}$ \\
\hline $\begin{array}{c}4^{\text {a do }} \\
\text { EF }\end{array}$ & 60 & 322 & 49 & 324 \\
\hline $\begin{array}{c}8^{\text {a do }} \\
\text { EF }\end{array}$ & 100 & 400 & 100 & 400 \\
\hline $\begin{array}{c}3^{\text {a do }} \\
\text { EM }\end{array}$ & 111 & 467 & 117 & 451 \\
\hline
\end{tabular}

Fonte: Saeb/Inep/Mec, 1997

Esses limites, inferiores e superiores, apresentados na Tabela 2, são usados, desde 1997 para o cálculo do Ideb, a partir do SAEB, para o Brasil (rede privada e pública; urbanas e rurais) e para os dados agregados por unidade da federação e, a partir da Prova Brasil de 2005, para municípios (rede municipal e estadual) e para as escolas.

O indicador de rendimento, $P_{j}$, é obtido conforme (3), onde a proporção de aprovados em cada uma das séries da etapa considerada, $p^{r}$ é calculada diretamente do

Censo Escolar ${ }^{8}$. Se $p^{r}(r=1,2, \ldots, \eta$ em que $\eta$ é o número de séries com taxa de aprovação positiva) é a taxa de aprovação da $r$-ésima série da etapa educacional considerada, então o tempo médio de duração da série é:

$$
T_{j i}=\sum_{r=1}^{n} \frac{1}{p^{r}}=\frac{\eta}{P_{j i}}
$$

Na equação (3), $P_{j i}$ é a taxa média de aprovação na etapa educacional no ano $i$. Note-se que, na ausência de evasão durante a etapa e em equilíbrio

\footnotetext{
${ }^{8}$ Para o cálculo de $\mathrm{T}_{\mathrm{ji}}$, o tempo médio para a conclusão de uma série, foram utilizados os dados de aprovação de cada uma das séries das três etapas de ensino: $1^{\mathrm{a}}$ e $2^{\mathrm{a}}$ fase do ensino fundamental e ensino médio. Para a operacionalização do indicador, convencionou-se o critério de considerar como inexistentes as séries que apresentavam taxa de aprovação zero.
}

estacionário, $\frac{\eta}{P_{j i}}$ fornece o tempo médio para conclusão de uma etapa para os alunos da unidade $j\left(\mathrm{~T}_{\mathrm{ji}}\right)$. Considerando $P$ o inverso do tempo médio para conclusão de uma série, então, $P_{j i}=\frac{1}{T_{j i}}$ e assim, se obtém o $I D E B_{j i}=\frac{N_{j i}}{P_{j i}}$, ou seja, o indicador fica sendo a pontuação no exame padronizado ajustada pelo tempo médio, em anos, para conclusão de uma série naquela etapa de ensino.

Tanto a taxa de aprovação como o Ideb e projeções, calculados para os estados da Região Sudeste, para os anos de 2005, 2007 e 2009, para as redes estadual, municipal e pública, serão explicitados nas seções seguintes.

\section{III.3 CÁlCULO DAS METAS \\ INTERMEDIÁRIAS PARA OS ESTADOS DA REGIÃo SUDESTE: PROJEÇÕES}

De acordo com Fernandes (2007b), o Ideb é o indicador objetivo para a verificação do cumprimento das metas fixadas no Termo de Adesão ao Compromisso Todos pela Educação, eixo do PDE, que trata da educação básica e, nesse âmbito, é que se enquadra a ideia das metas intermediárias para o Ideb. A lógica é a de que para que o Brasil chegue à média 6,0 em 2021, período estipulado, tendo como base a simbologia do bicentenário da Independência em 2022, cada sistema deve evoluir segundo pontos de partida distintos, e com esforço maior daqueles que partem em pior situação, com um objetivo implícito de redução da desigualdade educacional.

A definição da meta nacional para o Ideb em 6,0 significa dizer que o país deverá atingir em 2021, considerando os anos iniciais do ensino fundamental, o nível de qualidade educacional, em termos

\begin{tabular}{|l|l|l|l|}
\hline Cen & ISSN: 1984-3151 & www.unibh.br/revistas/exacta/ & Vol. 3 N. ${ }^{\text {2 }}$ (2010) \\
\hline
\end{tabular}


de proficiência e rendimento (taxa de aprovação), da média dos países desenvolvidos (membros da OCDE) observada atualmente. Essa comparação internacional foi possível devido a uma técnica de compatibilização entre a distribuição das proficiências observadas no Programme for Internacional Student Assessment (PISA) ${ }^{9}$ e no Saeb.

Fernandes (2007b) denota que, tecnicamente, para projetar as trajetórias esperadas para o Ideb ao longo do tempo, tanto para o Brasil como para os demais níveis de abrangência, parte-se do princípio de que essas trajetórias têm o comportamento de uma função logística, comportamento ilustrado pelo gráfico da Figura 1. Neste artigo, será explicitado o cálculo para as unidades federativas ${ }^{10}$, objeto deste estudo.

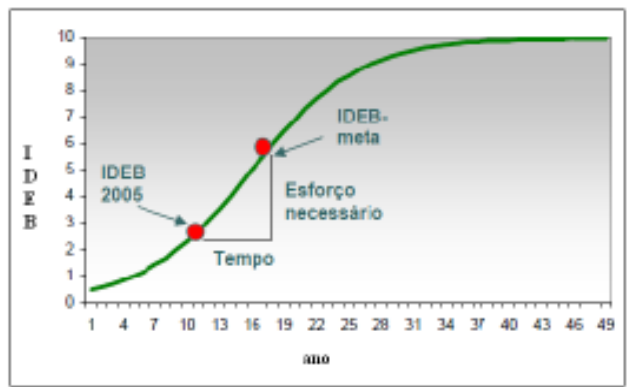

Figura 1 - Comportamento esperado para a trajetória do Ideb ao longo dos anos
Para um dado "esforço", obtém-se ao longo do tempo uma redução gradativa no ritmo e amplitude do crescimento do indicador. A segunda premissa técnica assumida é a de que, para o Brasil alcançar a meta estipulada no tempo adequado, a contribuição em esforço de cada rede de ensino e escola deve partir de metas individuais diferenciadas. Por fim, considera-se ainda que o esforço a ser empregado por cada esfera deve objetivar, além do alcance das metas intermediárias de curto prazo, a convergência dos Idebs atingidos pelas demais redes a médio e longo prazos, ou seja, os esforços de cada rede deve também contribuir para a redução das desigualdades em termos de qualidade educacional.

Para cada um dos Estados da Região Sudeste, é possível definir a trajetória do Ideb que contribuirá para que o Brasil atinja a meta escolhida no prazo definido. Para o cálculo das metas intermediárias e finais, dos Estados, adotase um processo semelhante ao descrito para o Brasil ${ }^{11}$. No entanto, no caso do País como um todo, tomam-se para o cálculo os parâmetros:

- Ideb inicial (2005), com $\mathrm{t}=0$ como valor inicial,

- meta do Ideb,

\footnotetext{
${ }^{9}$ Programa internacional de avaliação comparada, cuja principal finalidade é produzir indicadores sobre a efetividade dos sistemas educacionais, avaliando o desempenho de alunos na faixa dos 15 anos, idade em que se pressupõe o término da escolaridade básica obrigatória na maioria dos países. O PISA é desenvolvido e coordenado internacionalmente pela Organização para Cooperação e Desenvolvimento Econômico (OCDE), havendo em cada país participante uma coordenação nacional. No Brasil, o PISA é coordenado pelo Instituto Nacional de Estudos e Pesquisas Educacionais Anísio Teixeira (INEP).

${ }^{10}$ Para maiores informações sobre a metodologia, para Brasil, municípios e escolas, ler Fernandes $2007 b$.
}

\footnotetext{
${ }^{11}$ Para as projeções do Brasil utilizou-se o valor do Ideb em $2005(\mathrm{t}=0)$ como o valor inicial; a meta para o Brasil e o tempo para o seu alcance. Os anos definidos para que a meta do Ideb para o Brasil seja atingida são diferentes para cada fase de ensino, pois a meta de Ideb igual a 6,0 está relacionada à coorte que ingressará no ensino fundamental no ano de 2017. Desta forma, sem percalços (reprovações e abandonos) esta coorte deverá concluir a $1^{\text {a }}$ fase no ano 2021, a $2^{\text {a }}$ fase em 2025 e o ensino médio em 2028
} 
- tempo para o seu alcance ${ }^{12}$, com base em um objetivo de longo prazo: a convergência entre as redes. No caso do Brasil, o objetivo seria de curto prazo.

De posse destes dados, calculou-se o "esforço" necessário para se chegar à meta por meio da equação (4):

$$
\begin{gathered}
\text { ideb }_{i t}=\frac{1}{1+e^{-\left(\ln \left(\frac{i d e b_{i 0}}{10-i d e b_{i 0}}\right)+\gamma_{i} * t\right)}}(4) \\
t=\left\{\begin{array}{l}
0, \ldots, 16 \text { para metas da } 1^{\mathrm{a}} \text { fase do } \\
\text { Ensino Fundamental } \\
0, \ldots, 20 \text { para metas da } 2^{\mathrm{a}} \text { fase do } \\
\text { Ensino Fundamental } \\
0, \ldots, 23 \text { para metas do Ensino } \\
\text { Médio }
\end{array}\right.
\end{gathered}
$$

Onde:

t: tempo em anos, desde o ano do Ideb inicial

i: município, UF, Brasil, rede de ensino ou escola

ideb $_{\text {it: }}$ valor do Ideb no ano $\mathrm{t}$ para determinado $\mathbf{i}$

ide $_{\mathbf{i} 0}$ : Ideb inicial $(\mathrm{t}=0)$ para determinado i

yi: esforço individual empreendido para o alcance da meta proposta

$\mathrm{O}$ esforço $(\gamma \mathbf{i})$ garante que a meta para o Ideb do Brasil seja atingida no tempo esperado. Mantendo esse esforço encontrado constante, observou-se em quantos anos o Ideb do Brasil se aproximaria de um valor de convergência definido como 9,9, próximo ao máximo que o Ideb pode atingir por definição, já que $0 \leq$ Ideb $\leq 10$. Esse número de anos,

${ }^{12}$ Os anos definidos para que a meta do Ideb para o Brasil seja atingida são diferentes para cada fase de ensino, pois a meta de Ideb $=6,0$ está relacionada à coorte que ingressará no ensino fundamental no ano de 2017, ou seja, deverá concluir a $1^{a}$ fase no ano 2021, a $2^{\text {a }}$ fase em 2025 e o ensino médio em 2028. denominado aqui como sendo o 'tempo de convergência', ou $\lambda$, será utilizado para o cálculo das metas, intermediárias e finais, dos municípios, unidades da Federação e escolas.

Ressalta-se que o procedimento do cálculo dos esforços e metas intermediárias dos Estados (válido também para municípios e escolas), leva em consideração o Ideb inicial observado, fazendo com que cada rede obtenha uma trajetória diferente para o índice ao longo dos anos. Entretanto, conforme o proposto por esta metodologia é garantido que a desigualdade entre eles se reduza até que, em $\boldsymbol{\lambda}$, todos tenham o mesmo valor de Ideb $(9,9)$. A Figura 2, a seguir, exemplifica a simulação da trajetória do Ideb (considerando a $1^{\mathrm{a}}$ fase do EF) para o Brasil e dois Estados diferentes, até que seja alcançada a meta de convergência.

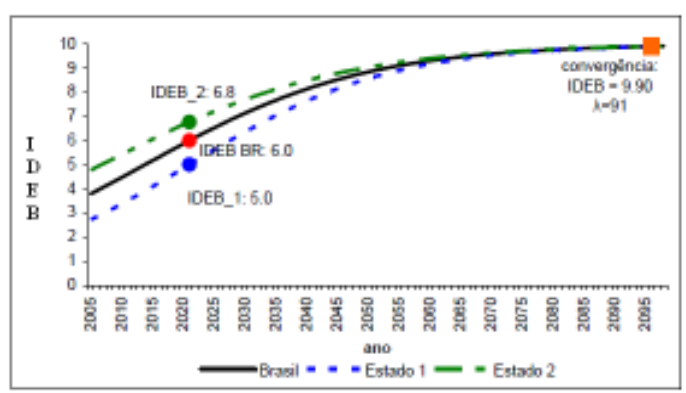

Figura 2 - Trajetória do Ideb para o Brasil e Estados: 2005 - $20961^{\text {a }}$ fase do ensino fundamental

No gráfico é possível observar que em 2021, ano estabelecido para que o Brasil atinja a meta igual a 6,0, o Estado 1 apresenta Ideb igual a 5 e o Estado 2, Ideb igual a 6,8. Cada Estado (município, rede ou escola) deverá despender um esforço diferente para que, em 2096 (após 91 anos), a desigualdade apresentada pelo Ideb desapareça.

A título de conclusão, para o cálculo das metas intermediárias bianuais, válidos para o Brasil, Estados, redes e escolas, foram adotados alguns procedimentos, tais como o estabelecimento da taxa de aprovação

\begin{tabular}{|l|l|l|l|}
\hline Centur & ISSN: 1984-3151 & www.unibh.br/revistas/exacta/ & Vol. 3 N. ${ }^{\circ} 2$ (2010) \\
\hline
\end{tabular}


mínima de $65 \%$ para a projeção do Ideb e uma técnica de suavização das metas intermediárias para os primeiros anos do Compromisso Todos pela Educação, posto que, a evolução da qualidade está relacionada ao tempo de exposição das gerações ao novo sistema e às mudanças no foco da política educacional. A partir da metodologia apresentada, é possível obter os esforços individuais necessários e as trajetórias a serem percorridas pelas redes de ensino e até mesmo pelas unidades escolares que tiverem Ideb, para que o País atinja em 2022 o nível de qualidade desejável à educação brasileira.

\section{ANÁLISE E RESULTADOS}

Afirmam Soares e Figueiredo (2010) que o Ideb, ao considerar tanto o fluxo escolar e o resultado em testes padronizados (Saeb e Prova Brasil), pretende indicar a qualidade do sistema de ensino brasileiro. Afinal, entende-se que um sistema de ensino é bem sucedido quanto consegue ter bons resultados em testes e também manter os alunos na escola sem tanta evasão e repetência.

Dos 1.538 municípios da Região Sudeste que participaram da medição do Ideb em 2005 e 2007, na quarta série do ensino fundamental, $1.110 \quad(72,2 \%)$ alcançaram as metas em 2007. Em Minas Gerais, o total foi de 69,6\%; Espírito Santo, 96,1\%; Rio de Janeiro, 70,3\%; e São Paulo, 72,7\%. Para esta mesma série, $81,2 \%$ dos municípios brasileiros alcançaram a meta de 3,9 pontos.

$\mathrm{Na}$ oitava série do ensino fundamental, a região teve 1.586 municípios com Ideb pesquisados nos anos de 2005 e 2007. Destes, 1.106 (69,7\%), alcançaram a meta em 2007, com percentuais assim distribuídos pelas quatro unidades federativas que compõem a região: Minas Gerais (78,7\%), Espírito Santo $(75,6 \%)$, Rio de Janeiro $(29,3 \%)$ e São Paulo $(62,9 \%)$. Na oitava série, o desempenho do país foi de $72,5 \%$. O Ideb do Ensino Médio nacional passou de 3,4 pontos em 2005 para 3,5 pontos em 2007.

\section{IV.1 O IDEB CALCULADO PARA AS SÉRIES INICIAIS DO ENSINO FUNDAMENTAL}

Os dados do Ideb apresentados, para 2005, 2007 e 2009 demonstram uma nítida evolução do índice na Região Sudeste. Ressalta-se que ao final deste artigo, as Tabelas de 5 a 13 evidenciam valores calculados para a Prova Brasil (Taxa de Aprovação), de onde é retirado o Indicador de Rendimento (P) e valores para o Saeb (escores de Língua Portuguesa e Matemática), que resulta na Nota Padronizada $(\mathrm{N})$. Em seção anterior, foi demonstrado que o produto $(\mathrm{N}) *(\mathrm{P})$ tem por resultado o Índice de Desenvolvimento da Educação Básica.

A Figura 3 mostra a série histórica do Ideb para os quatro Estados que compõem a Região Sudeste em relação a $4^{\mathrm{a}}$ série $/ 5^{\circ}$ ano do Ensino Fundamental. Observa-se que todas as unidades federativas evoluíram, ultrapassando as metas estabelecidas pelo PDE (vide Tabela 14 em anexo).

No estado de Minas Gerais, o Ideb referente à rede estadual nas séries iniciais do ensino fundamental, atingiu a meta projetada, entretanto, o índice referente às escolas privadas, para 2009, ficou aquém da projeção (vide Tabelas 5, 6, 7 e 14 em anexo), fato semelhante ocorrido em 2007. As médias padronizadas sofreram acréscimo em todos os casos, assim como as pontuações obtidas em Matemática e Língua Portuguesa.

Para o Estado de São Paulo, o Ideb das escolas estaduais e privadas nas séries iniciais do ensino fundamental superou os índices projetados para o ano de 2009 (vide Tabela 14 em anexo). Ressalta-se que, no caso das escolas privadas, no ano de 2007 , o índice obtido foi inferior ao projetado, 
mas em 2009, o Ideb sofreu um acréscimo de oito décimos, ultrapassando em um décimo o índice projetado para 2011. Nas médias padronizadas houve progresso nos resultados de todas as redes avaliadas. No cômputo geral, as pontuações obtidas na Prova Brasil/Saeb evoluíram tanto de 2005 para 2007, como de 2007 para 2009. No entanto, de 2005 para 2007, houve um decréscimo da pontuação das escolas estaduais na disciplina Matemática e, nas escolas privadas, em ambas as disciplinas.

O Estado do Espírito Santo apresentou notável evolução em todos os índices apurados nas séries iniciais do ensino fundamental, ultrapassando os índices previstos para 2011. As notas médias padronizadas prosperam desde 2005, exceção dada as escolas privadas, onde no período de 2005 para 2007, houve um decréscimo de 0,05 na pontuação geral (6,39 para 6,34 pontos), alcançando o escore de 7,04 em 2009. Considerando o índice total, as pontuações obtidas nas disciplinas Matemática e Língua Portuguesa têm apresentado uma série crescente, apesar de, tanto as escolas estaduais, como as privadas terem apresentado decréscimo em suas pontuações de 2005 para 2007, em relação à disciplina Língua Portuguesa.

Para as séries iniciais o Estado do Rio de Janeiro alcançou o índice projetado para 2009, e a série histórica evidencia evolução dos índices alcançados desde o ano de 2005. No entanto, analisando-se separadamente a rede estadual e privada, verifica-se que os índices obtidos ficaram aquém dos projetados, com a rede estadual obtendo o índice 4,0 (projetado de 4,1) e o segmento privado alcançado o Ideb 5,9 (projetado de 6,1). A análise das pontuações obtidas nas disciplinas contempladas pela Prova Brasil/Saeb indicam progresso em Matemática, tanto no que se refere à pontuação total nos segmentos escolas estaduais e privadas.

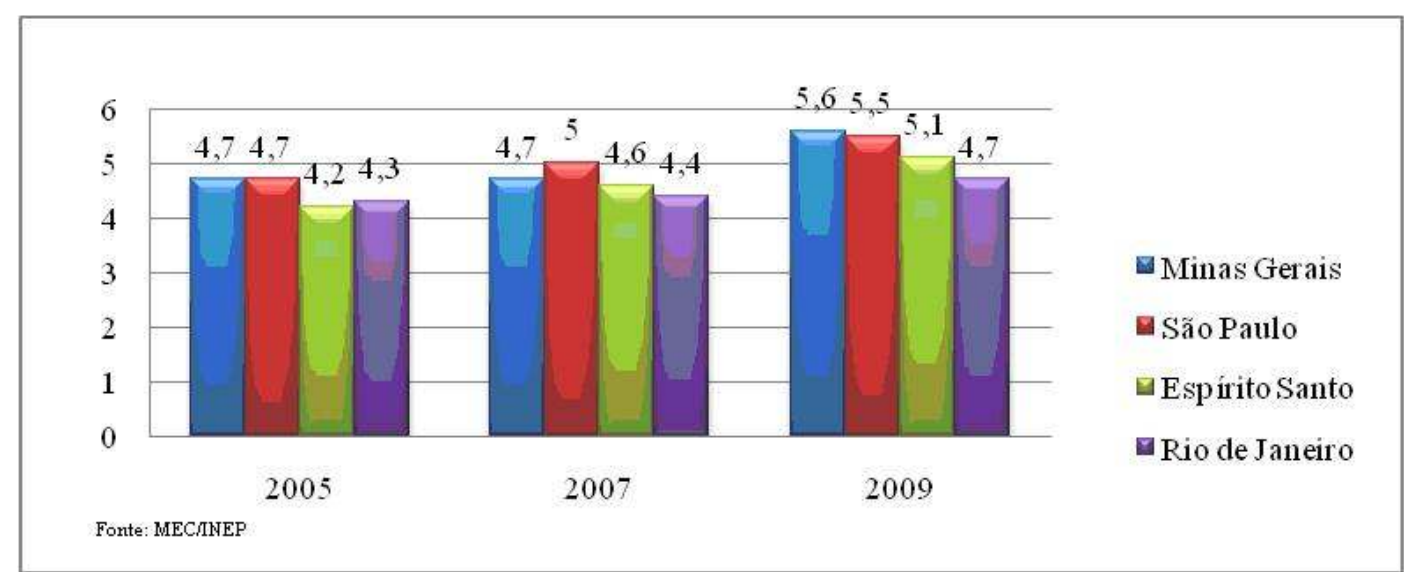

Figura 3- Ideb calculado para Região Sudeste, na 4ª́rie/5º ano do Ensino Fundamental, 2005, 2007 e 2009. 


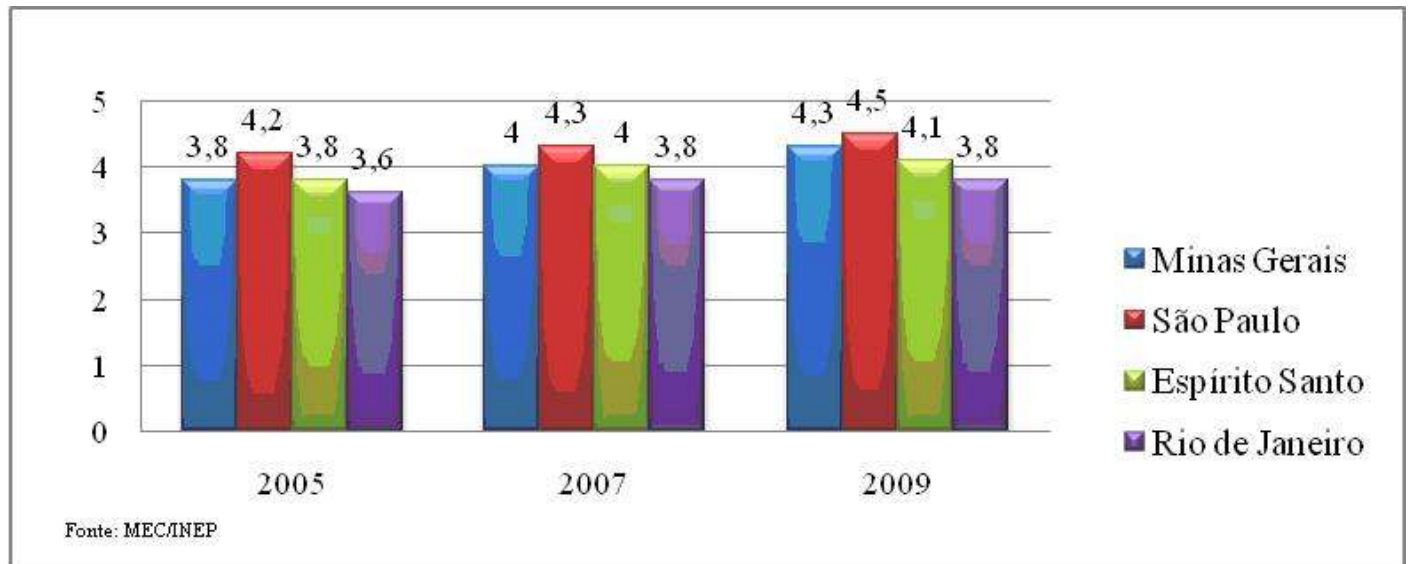

Figura 4 - Ideb calculado para Região Sudeste, na $8^{\mathrm{a}}$ série/9º ano do Ensino Fundamental, 2005, 2007 e 2009.

Em Língua Portuguesa, o escore total demonstrou que houve um decréscimo da pontuação obtida de 2005 para 2007, recuperada em 2009 (escolas estaduais e privadas). No caso das escolas privadas, a involução se deu de 2007 para 2009, decrescendo 0,29 pontos o escore (209,76 para 209,47 pontos).

\section{IV.2 O IDEB CALCULADO PARA AS SÉRIES FINAIS DO ENSINO FUNDAMENTAL}

A Figura 4 denota a série histórica do Ideb para as séries finais do Ensino Fundamental, relativas às unidades federativas da Região Sudeste. A exceção do Estado do Rio de Janeiro, que manteve de 2007 para 2009 o índice, observa-se o progresso do Ideb para os demais estados.

Em Minas Gerais, nas séries finais do Ensino Fundamental, assim como em 2009, as escolas privadas não alcançaram a meta projetada em 2007. No entanto, em ambos os períodos, as médias padronizadas da série histórica iniciada em 2005 apresentaram crescimento, assim como as pontuações obtidas nas disciplinas avaliadas, excetuando-se o escore obtido pelas escolas privadas em Matemática, de 2005 para 2007 que sofreu um decréscimo de 1,43 .

O Ideb estadual e, sobremaneira, o referente às escolas estaduais paulistas alcançou os escores projetados para 2009, e no caso das escolas estaduais, o índice obtido já superou o projetado para 2011. As médias padronizadas também apresentaram evolução, fato que se repetiu para as pontuações obtidas em Matemática e Língua Portuguesa. No caso da rede privada, verificou-se que os índices vêm decrescendo desde $2005 \quad(6,3 / 2005$, $6,2 / 2007$ e 6,0/2009), não tendo, portanto, este segmento alcançado os índices projetados em nenhum dos biênios avaliados. Da mesma forma, as médias e escores obtidos nas disciplinas avaliadas foram decrescentes. Em Matemática a pontuação obtida em 2005 foi 305,37 e a de 2009, 280,59, decréscimo de 24,78 pontos. Para a Língua Portuguesa, a pontuação do ano de 2005 foi 285,78 e a de 2009, 280,59, revelando um decréscimo de 5,19 pontos.

Para o Estado do Espírito Santo, os índices projetados para as séries finais (vide 8, 9 e 10) também foram alcançados, em todas as redes avaliadas. As notas médias padronizadas vêm se portando de maneira progressiva desde o início da série histórica em 2005, com exceção feita as escolas estaduais que, de 2005 para 2007 , tiveram um decréscimo de 0,02 . Os escores obtidos para a disciplina Matemática indicam que o resultado para o ano de 2009 foi inferior ao obtido em 2005,

\begin{tabular}{|l|l|l|l|}
\hline Con & ISSN: 1984-3151 & www.unibh.br/revistas/exacta/ & Vol. 3 N. ${ }^{\text {o }} 2$ (2010) \\
\hline
\end{tabular}


ficando a série histórica assim representada: 247,76/2005; 243,82/2007 e 246,37/2009.

Nas séries finais do Ensino Fundamental fluminense, apesar dos índices projetados terem sido alcançados, verificou-se que não ocorreu evolução de 2007 para 2009, ambos com índice 3,8. Entretanto, nos segmentos escolas estaduais e escolas privadas, verificou-se que, de 2005 para 2007, não houve evolução nas duas redes, mas os índices projetados para 2009 foram atingidos, Esta análise também permitiu verificar que houve aumento das médias padronizadas. As pontuações obtidas nas disciplinas avaliadas também sofreram evolução desde 2005, exceção feita à rede privada, que em 2007 obteve pontuação inferior à de 2005 , recuperando-se em 2009.

\section{IV.3 O IDEB CALCULADO PARA A $3 .^{a}$ SÉRIE DO ENSINO MÉDIO}

A Figura 5 apresenta os valores da série histórica do Ideb para a $3^{\mathrm{a}}$ série do Ensino Médio, relativas às unidades federativas que compõem a Região Sudeste.

Em 2009, os Estados de São Paulo e Minas Gerais se destacaram, apresentando Ideb no valor de 3,9, seguidos do Espírito Santo com 3,8 e Rio de Janeiro com 3,3. Em 2007, o maior índice foi o obtido pelo Estado de São Paulo $(3,9)$, seguido por Minas Gerais $(3,8)$, Espírito Santo $(3,6)$ e Rio de Janeiro com 3,2. Para 2005, os valores do Ideb denotavam que a maior pontuação foi obtida pelos Estados de Minas Gerais e Espírito Santo $(3,8)$, seguido pelo Estado de São Paulo $(3,6)$ e Rio de Janeiro com índice igual a 3,3.

Em Minas Gerais, as escolas privadas não alcançaram o índice projetado tanto em 2007, como em 2009. A média padronizada das escolas estaduais regrediu de 4,66 para 4,59, entretanto, as pontuações obtidas nas avaliações do Saeb vêm crescendo a cada edição do Ideb.

O panorama do Ensino Médio verificado no Estado de São Paulo e nas escolas estaduais isoladamente, no que se refere aos índices obtidos, é similar ao do ensino fundamental, apresentando índices crescentes desde o início da série histórica. Os índices projetados para 2011 já foram alcançados na avaliação de 2009 (vide tabelas 11, 12 e 13). Nos escores obtidos nas avaliações Saeb, a pontuação geral em Matemática aumentou de 279,43 em 2007, para 278,10 em 2009. Em relação à Língua Portuguesa, as pontuações são crescentes, sobremaneira nas escolas estaduais, desde o ano de 2005.

As escolas privadas paulistas não alcançaram o Ideb projetado para 2009 (vide Tabelas 14, 15 e 16 em anexo), ficando aquém do índice desejável. A média padronizada nesta edição decresceu $(0,41$ pontos $)$ com relação à obtida em 2007. Diminuíram também os escores para as avaliações Saeb, que se mostraram inferiores às do ano de 2007. 


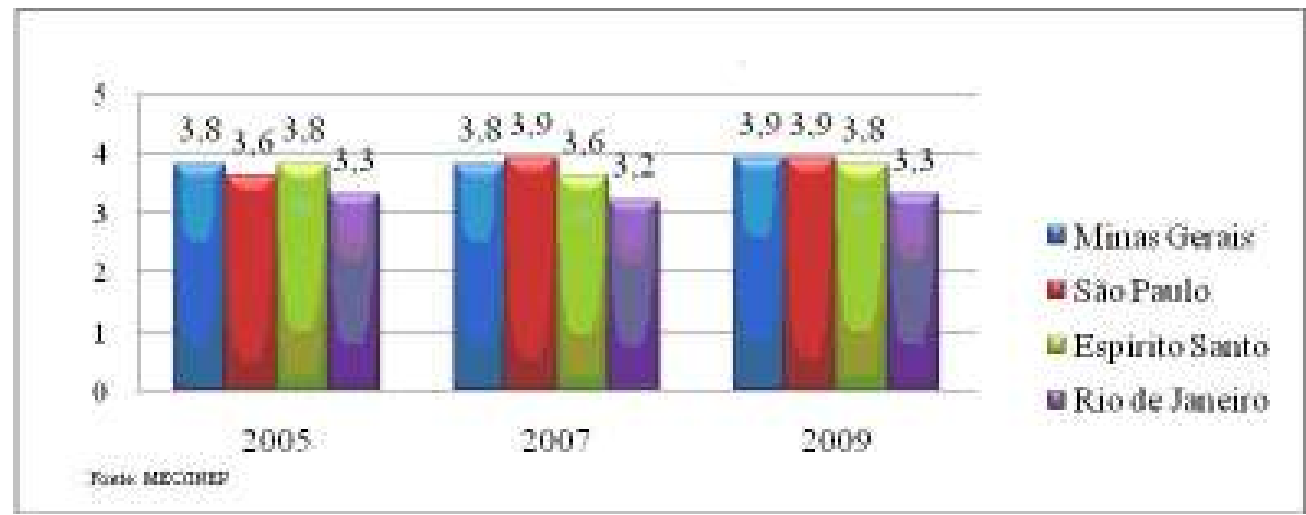

Figura 5 - Ideb calculados para Região Sudeste, na 3ª́rie do Ensino Médio, 2005, 2007 e 2009.

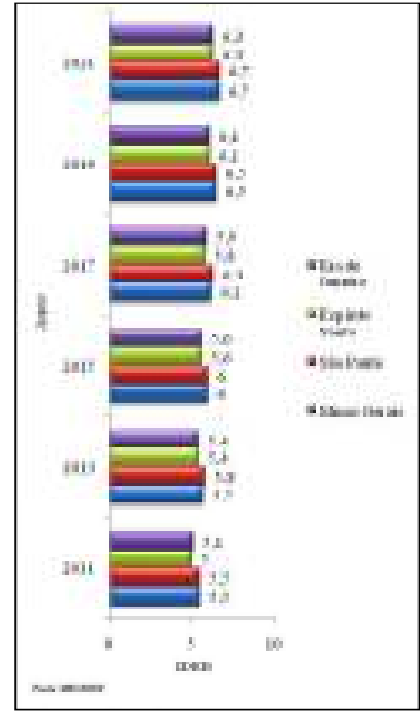

Figura 6 - Projeções do Ideb para a $4^{\mathrm{a}}$ série $/ 5^{\circ}$ ano do Ensino Fundamental.

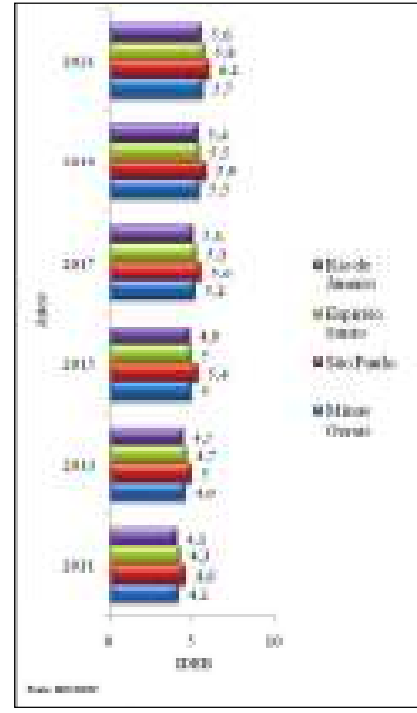

Figura 7 - Projeções do Ideb para a $8^{\text {a }}$ série $/ 9^{\circ}$ ano do Ensino Fundamental.

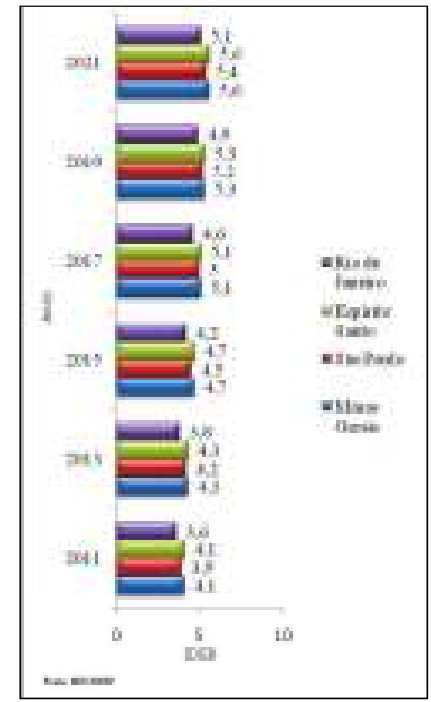

Figura 8 - Projeções do Ideb para a $3^{\mathrm{a}}$ série do Ensino Médio, 2011-2021.
Em relação à disciplina Matemática, o escore sofreu um decréscimo de 337,98 para 319,03 pontos, representando uma diferença de 18,95 pontos. Para a Língua Portuguesa, o decréscimo observado foi de 9,69 pontos, indo de 310,86 em 2007 para 301,17 em 2009.

O Espírito Santo não alcançou a meta prevista para o ensino médio em 2009, entretanto, as notas médias padronizadas demonstraram progresso (vide Tabela 16 em anexo).

Ressalta-se, diante deste quadro, que as escolas estaduais apresentaram Ideb superior ao projetado, em detrimento das escolas privadas, que não alcançaram a meta para 2009. As notas médias padronizadas (nível estadual) sofreram decréscimo de 2005 para 2007, fato que se repetiu em 2009, enquanto que nas escolas privadas o decréscimo foi verificado de 2007 para 2009. As pontuações obtidas em

\begin{tabular}{|l|l|l|l|}
\hline Cen & ISSN: 1984-3151 & www.unibh.br/revistas/exacta/ & Vol. 3 N. ${ }^{\circ} 2(2010)$ \\
\hline
\end{tabular}


Matemática e Língua Portuguesa (nível estadual) sofreram decréscimo de 2005 para 2007. Para as escolas privadas, observou-se um decréscimo dos escores de 2007 para 2009 em Matemática e discreto aumento de 0,3 pontos para a disciplina Língua Portuguesa $(312,64$ para 312,94 pontos).

No Estado do Rio de Janeiro, desde 2007, o Ideb estadual projetado não foi alcançado, sugerindo certa paralisia (grifo da autora) da série histórica $(3,3 / 2005$, 3,2/2007, 3,3/2009). Na rede estadual este pormenor ficou ainda mais evidente, com a série histórica praticamente estanque para todas as edições do Ideb $(2,8 / 2005$, 2,8/2007, 2,8/2009). Faz-se necessário frisar que, apesar das escolas privadas terem atingido o índice projetado para 2007 e 2009, as médias padronizadas e a pontuação nas disciplinas avaliadas, para a rede estadual têm demonstrado modesta evolução.

As Figuras 6, 7 e 8 denotam as projeções do Ideb, de 2011 a 2021, para os Estados de Minas Gerais, São Paulo, Espírito Santo e Rio de Janeiro. Os maiores escores, para o ano 2021 são observados para a $4^{\mathrm{a}}$ série $/ 5^{\circ}$ ano do Ensino Fundamental, para as unidades federativas de São Paulo e Minas Gerais (6,7), seguidos por Espírito Santo e Rio de Janeiro $(6,1)$. Em relação a 8 série $/ 9^{\circ}$ ano do Ensino Fundamental, apenas o Estado de São Paulo $(6,1)$ atingirá a meta, seguido pelo Espírito Santo $(5,8)$, Minas Gerais $(5,7)$ e Rio de Janeiro $(5,6)$. Atingir as metas para a $3^{\mathrm{a}}$ série do Ensino Médio constitui-se em grande desafio, posto que pelas projeções aferidas, nenhuma das unidades federativas alcançará a média 6,0, com Minas Gerais e Espírito Santo com índice 5,6, São Paulo com 5,4 e por último, o Rio de Janeiro, com Ideb 5,1.

\section{CONSIDERAÇÕES FINAIS}

O Ideb é o "termômetro da qualidade" da educação básica brasileira e sua proposta, como monitoramento objetivo da qualidade dos sistemas de ensino, a partir da combinação entre fluxo e aprendizagem escolar, devem se tornar públicas. A metodologia, bem como, os resultados bienais devem ser analisados e demonstrados, para que os níveis de abrangência (Estados, municípios, redes e instituições escolares) que alcançaram os objetivos pré-fixados tenham as estratégias adotadas, reforçadas e divulgadas. Por outro lado, aqueles níveis que não atenderam ao que foi projetado, devem buscar no insucesso, respostas para garantir que as falhas sejam sanadas.

No que tange às projeções alcançadas, o questionamento frequente deverá ser em torno de quais estratégias devem ser adotadas para manutenção e/ou superação dos índices adquiridos. Diante de um índice com repercussão nacional desfavorável, é recomendável avaliar o que não saiu a contento, ao invés de buscar culpados pelo mau êxito. Acreditam alguns segmentos, que se a postura é de avaliação do Ideb, esse índice tem que ser decomposto, denotando assim o que melhorou ou piorou nos ensinos público e privado, onde implementar melhorias, além do monitoramento freqüente, no que tange à relação aprovação e escores obtidos pela Prova Brasil/ Saeb.

A análise dos índices para os Estados da Região Sudeste, mostrou que há evolução no Ideb para as séries do Ensino Fundamental, exceção feita para a $8^{\mathrm{a}}$ série $/ 9^{\circ}$ ano no Estado do Rio de Janeiro, que manteve a mesma média $(3,8)$ para os anos de 2007 e 2009. Para o Ensino Médio o desafio para os próximos anos se mostra bem maior, pois, apesar das médias discretas, todos os Estados ficaram abaixo da média 4,0. Estes índices baixos podem 
ser explicados pela migração discente rede pública-rede privada, principalmente na terceira série, quando muitos estudantes buscam uma preparação específica para o vestibular. Como muitos desses indivíduos não tiveram a mesma base educacional, o resultado em avaliações de larga escala, como a Prova Brasil/Saeb, que compõem o Ideb tende a estacionar ou decrescer.

Conclui-se com este artigo, que as lições deixadas pelas unidades federativas que alcançaram os objetivos propostos pelo PDE, podem ser assim entendidas: 0 importante é, mesmo diante de índices favoráveis, não se acomodar, pois a responsabilidade e compromisso ante ao sucesso alcançado, tornam-se bem maiores para os anos subsequentes. Em contrapartida, esforços devem ser somados para que adversidades de todo tipo sejam transformadas em estímulos, visando à melhoria dos índices da educação básica brasileira, pois, se a Região Sudeste, detentora dos melhores índices educacionais do país, ainda não alcançou a excelência dos países desenvolvidos, o que dizer das demais regiões?

\section{REFERÊNCIAS}

ALVES, F.. Qualidade da Educação Fundamental: integrando desempenho e fluxo escolar. Ensaio. Avaliação e Políticas Públicas em Educação, v. 15, p. 525-542, 2007.
FERNANDES, R.. Índice de Desenvolvimento da Educação Básica (Ideb). Brasília, DF: Instituto Nacional de Estudos e Pesquisas Educacionais Anísio Teixeira - INEP (Série Documental. Textos para Discussão; 26), 2007a.

FERNANDES, R.. IDEB: monitoramento objetivo da qualidade dos sistemas a partir da combinação entre fluxo e aprendizagem escolar. In O Plano de Desenvolvimento da Educação - Em Questão $N^{o}$ 4, Mariângela Graciano (Org.). São Paulo: Ação Educativa/Observatório da Educação, 2007b.

INSTITUTO NACIONAL DE ESTUDOS E PESQUISAS EDUCACIONAIS ANÍSIO TEIXEIRA (INEP). Ideb: resultados e metas. Disponível em:< http://www.inep.gov.br>. Acesso em: 12 mar. 2009.

SOARES, C. M. M.; FIGUEIRÊDO, L. Nível de Renda e a Qualidade da Educação nos Municípios Brasileiros. XIV Seminário sobre Economia Mineira. Diamantina-MG. Org. CEDEPLAR/FACE (UFMG), 2010. 


\section{ANEXOS}

Tabela 5 - Prova Brasil, Saeb e Ideb calculados para o Ensino Fundamental (Séries Iniciais), para a Região Sudeste, 2005

\begin{tabular}{|c|c|c|c|c|c|c|c|}
\hline \multirow{2}{*}{$\begin{array}{l}\text { Região/ } \\
\text { Unidade da } \\
\text { Federação }\end{array}$} & \multirow[b]{2}{*}{ Rede } & \multicolumn{2}{|c|}{ Taxa de Aprovação -2005 } & \multicolumn{3}{|c|}{ Nota SAEB - 2005} & \multirow{2}{*}{$\begin{array}{c}\text { IDEB } \\
2005 \\
(\mathrm{~N} \times \mathrm{P})\end{array}$} \\
\hline & & $\mathrm{SI} \mathrm{a} 4^{\mathrm{a}}$ & $\begin{array}{c}\text { Indicador de } \\
\text { Rendimento } \\
\text { (P) }\end{array}$ & Matemática & $\begin{array}{c}\text { Língua } \\
\text { Portuguesa }\end{array}$ & $\begin{array}{c}\text { Nota Média } \\
\text { Padronizada } \\
(\mathrm{N})\end{array}$ & \\
\hline Sudeste & Total & 90,5 & 0,91 & 195,75 & 184,22 & 5,05 & $\overline{4,6}$ \\
\hline Sudeste & Estadual & 92,4 & 0,93 & 190,33 & 180,48 & 4,88 & 4,5 \\
\hline Sudeste & Privada (1) & 98,0 & 0,97 & 236,84 & 218,79 & 6,46 & 6,3 \\
\hline Minas Gerais & Total & 89,1 & 0,90 & 203,65 & 186,64 & 5,25 & 4,7 \\
\hline Minas Gerais & Estadual & 91,5 & 0,92 & 206,91 & 186,80 & 5,31 & 4,9 \\
\hline Minas Gerais & Privada & 98,4 & 0,99 & 252,67 & 233,46 & 7,03 & 6,9 \\
\hline Espírito Santo & Total & 84,1 & 0,86 & 191,43 & 179,72 & 4,89 & 4,2 \\
\hline Espírito Santo & Estadual & 78,3 & 0,78 & 184,85 & 178,98 & 4,75 & 3,7 \\
\hline Espírito Santo & Privada & 98,6 & 0,99 & 232,93 & 218,82 & 6,39 & 6,3 \\
\hline Rio de Janeiro & Total & 84,8 & 0,85 & 196,41 & 183,23 & 5,05 & 4,3 \\
\hline Rio de Janeiro & Estadual & 81,5 & 0,82 & 177,95 & 173,76 & 4,52 & 3,7 \\
\hline Rio de Janeiro & Privada & 96,9 & 0,97 & 220,24 & 206,84 & 5,93 & 5,7 \\
\hline São Paulo & Total & 94,5 & 0,95 & 191,81 & 183,70 & 4,97 & 4,7 \\
\hline São Paulo & Estadual & 95,7 & 0,96 & 182,79 & 177,86 & 4,69 & 4,5 \\
\hline São Paulo & Privada & 98,3 & 0,99 & 242,57 & 221,78 & 6,63 & 6,5 \\
\hline
\end{tabular}

Fonte: MEC/Inep.

Notas: (1) Médias da Prova Brasil/SAEB 2009 e Ideb 2009 calculados somente com as escolas urbanas.

Tabela 6 - Prova Brasil, Saeb e Ideb calculados para o Ensino Fundamental (Séries Iniciais), para a Região Sudeste, 2007

\begin{tabular}{|c|c|c|c|c|c|c|c|}
\hline \multirow[b]{2}{*}{$\begin{array}{l}\text { Região/ } \\
\text { Unidade da } \\
\text { Federação }\end{array}$} & \multirow[b]{2}{*}{ Rede } & \multicolumn{2}{|c|}{ Taxa de Aprovação -2007 } & \multicolumn{3}{|c|}{ Nota Prova Brasil/SAEB - 2007} & \multirow{2}{*}{$\begin{array}{c}\text { IDEB } \\
2007 \\
(\mathrm{~N} \times \mathrm{P})\end{array}$} \\
\hline & & $\mathrm{SI} \mathrm{a} 4^{\mathrm{a}}$ & $\begin{array}{c}\text { Indicador de } \\
\text { Rendimento } \\
\text { (P) }\end{array}$ & Matemática & $\begin{array}{c}\text { Língua } \\
\text { Portuguesa }\end{array}$ & $\begin{array}{c}\text { Nota Média } \\
\text { Padronizada } \\
\text { (N) }\end{array}$ & \\
\hline Sudeste & Total & 92,1 & 0,92 & 202,31 & 183,75 & 5,17 & $\overline{4,8}$ \\
\hline Sudeste & Estadual & 93,3 & 0,94 & 196,79 & 179,20 & 4,98 & 4,7 \\
\hline Sudeste & Privada (1) & 98,4 & 0,98 & 236,79 & 217,13 & 6,44 & 6,3 \\
\hline Minas Gerais & Total & 91,2 & 0,91 & 203,51 & 183,54 & 5,19 & 4,7 \\
\hline Minas Gerais & Estadual & 93,0 & 0,93 & 204,46 & 185,51 & 5,24 & 4,9 \\
\hline Minas Gerais & Privada & 98,5 & 0,99 & 248,20 & 226,09 & 6,82 & 6,7 \\
\hline Espírito Santo & Total & 88,2 & 0,89 & 200,43 & 183,02 & 5,12 & 4,6 \\
\hline Espírito Santo & Estadual & 83,8 & 0,84 & 194,52 & 178,05 & 4,92 & 4,1 \\
\hline Espírito Santo & Privada & 98,7 & 0,99 & 234,68 & 214,23 & 6,34 & 6,3 \\
\hline Rio de Janeiro & Total & 86,8 & 0,87 & 199,54 & 183,17 & 5,11 & 4,4 \\
\hline Rio de Janeiro & Estadual & 80,2 & 0,81 & 188,70 & 172,44 & 4,70 & 3,8 \\
\hline Rio de Janeiro & Privada & 97,0 & 0,97 & 226,94 & 209,76 & 6,11 & 5,9 \\
\hline São Paulo & Total & 95,0 & 0,96 & 204,02 & 185,41 & 5,23 & 5,0 \\
\hline São Paulo & Estadual & 95,9 & 0,96 & 193,76 & 176,71 & 4,88 & 4,7 \\
\hline São Paulo & Privada & 98,7 & 0,99 & 239,29 & 219,00 & 6,52 & 6,4 \\
\hline
\end{tabular}

Fonte: MEC/Inep.

Notas: (1) Médias da Prova Brasil/SAEB 2009 e Ideb 2009 calculados somente com as escolas urbanas.

\begin{tabular}{|l|l|l|l|}
\hline Cen & ISSN: 1984-3151 & www.unibh.br/revistas/exacta/ & Vol. 3 N. ${ }^{\text {2 }}$ (2010) \\
\hline
\end{tabular}


Tabela 7 - Prova Brasil, Saeb e Ideb calculados para o Ensino Fundamental (Séries Iniciais), para a Região Sudeste, 2009

\begin{tabular}{|c|c|c|c|c|c|c|c|}
\hline \multirow{2}{*}{$\begin{array}{l}\text { Região/ } \\
\text { Unidade da } \\
\text { Federação }\end{array}$} & \multirow[b]{2}{*}{ Rede } & \multicolumn{2}{|c|}{ Taxa de Aprovação -2009 } & \multicolumn{3}{|c|}{ Nota Prova Brasil/SAEB - 2009} & \multirow{2}{*}{$\begin{array}{c}\text { IDEB } \\
2009 \\
(\mathrm{~N} \times \mathrm{P})\end{array}$} \\
\hline & & $\mathrm{SI} \mathrm{a} 4^{\mathrm{a}}$ & $\begin{array}{c}\text { Indicador de } \\
\text { Rendimento } \\
\text { (P) }\end{array}$ & Matemática & $\begin{array}{c}\text { Língua } \\
\text { Portuguesa }\end{array}$ & $\begin{array}{c}\text { Nota Média } \\
\text { Padronizada } \\
\text { (N) }\end{array}$ & \\
\hline Sudeste & Total & 93,2 & 0,93 & 219,31 & 196,46 & 5,73 & 5,3 \\
\hline Sudeste & Estadual & 95,8 & 0,96 & 215,94 & 192,34 & 5,59 & 5,4 \\
\hline Sudeste & Privada (1) & 98,1 & 0,98 & 252,12 & 228,37 & 6,93 & 6,8 \\
\hline Minas Gerais & Total & 93,4 & 0,94 & 227,73 & 203,00 & 6,01 & 5,6 \\
\hline Minas Gerais & Estadual & 96,7 & 0,97 & 227,75 & 202,66 & 6,00 & 5,8 \\
\hline Minas Gerais & Privada & 98,5 & 0,98 & 260,66 & 236,38 & 7,24 & 7,1 \\
\hline Espírito Santo & Total & 90,8 & 0,91 & 213,78 & 193,29 & 5,56 & 5,1 \\
\hline Espírito Santo & Estadual & 91,3 & 0,92 & 210,73 & 188,78 & 5,42 & 5,0 \\
\hline Espírito Santo & Privada & 98,7 & 0,99 & 255,16 & 231,13 & 7,04 & 7,0 \\
\hline Rio de Janeiro & Total & 86,3 & 0,86 & 210,83 & 192,11 & 5,49 & 4,7 \\
\hline Rio de Janeiro & Estadual & 79,3 & 0,81 & 195,72 & 177,40 & 4,93 & 4,0 \\
\hline Rio de Janeiro & Privada & 96,6 & 0,97 & 229,61 & 209,47 & 6,16 & 5,9 \\
\hline São Paulo & Total & 95,9 & 0,96 & 220,55 & 196,79 & 5,76 & 5,5 \\
\hline São Paulo & Estadual & 97,2 & 0,98 & 212,91 & 189,36 & 5,48 & 5,4 \\
\hline São Paulo & Privada & 98,5 & 0,99 & 262,90 & 237,18 & 7,30 & 7,2 \\
\hline
\end{tabular}

Fonte: MEC/Inep.

Tabela 8 - Prova Brasil, Saeb e Ideb calculados para o Ensino Fundamental (Séries Finais), para a Região Sudeste, 2005

\begin{tabular}{|c|c|c|c|c|c|c|c|}
\hline \multirow{2}{*}{$\begin{array}{l}\text { Região/ } \\
\text { Unidade da } \\
\text { Federação }\end{array}$} & \multirow[b]{2}{*}{ Rede } & \multicolumn{2}{|c|}{ Taxa de Aprovação -2005 } & \multicolumn{3}{|c|}{ Nota SAEB - 2005} & \multirow{2}{*}{$\begin{array}{c}\text { IDEB } \\
2005 \\
(\mathrm{~N} \times \mathrm{P})\end{array}$} \\
\hline & & $5^{\mathrm{a}}$ a $8^{\mathrm{a}}$ & $\begin{array}{c}\text { Indicador de } \\
\text { Rendimento } \\
\text { (P) }\end{array}$ & Matemática & $\begin{array}{c}\text { Língua } \\
\text { Portuguesa }\end{array}$ & $\begin{array}{c}\text { Nota Média } \\
\text { Padronizada } \\
\text { (N) }\end{array}$ & \\
\hline Sudeste & Total & 83,5 & 0,83 & 246,17 & 237,53 & 4,73 & 3,9 \\
\hline Sudeste & Estadual & 82,1 & 0,82 & 236,17 & 229,81 & 4,43 & 3,6 \\
\hline Sudeste & Privada & 95,4 & 0,95 & 302,27 & 281,51 & 6,40 & 6,1 \\
\hline Minas Gerais & Total & 77,0 & 0,77 & 254,59 & 238,43 & 4,88 & 3,8 \\
\hline Minas Gerais & Estadual & 75,1 & 0,75 & 251,63 & 234,55 & 4,77 & 3,6 \\
\hline Minas Gerais & Privada & 94,5 & 0,95 & 319,93 & 288,74 & 6,81 & 6,4 \\
\hline Espírito Santo & Total & 79,9 & 0,80 & 249,95 & 234,46 & 4,74 & 3,8 \\
\hline Espírito Santo & Estadual & 77,3 & 0,77 & 247,76 & 227,00 & 4,58 & 3,5 \\
\hline Espírito Santo & Privada & 95,2 & 0,95 & 300,20 & 274,06 & 6,24 & 5,9 \\
\hline Rio de Janeiro & Total & 76,8 & 0,77 & 244,34 & 237,28 & 4,69 & 3,6 \\
\hline Rio de Janeiro & Estadual & 70,7 & 0,71 & 220,58 & 223,90 & 4,07 & 2,9 \\
\hline Rio de Janeiro & Privada & 92,7 & 0,93 & 285,08 & 269,50 & 5,91 & 5,5 \\
\hline São Paulo & Total & 89,9 & 0,90 & 241,96 & 237,36 & 4,66 & 4,2 \\
\hline São Paulo & Estadual & 88,2 & 0,88 & 230,22 & 228,45 & 4,31 & 3,8 \\
\hline São Paulo & Privada & 97,0 & 0,97 & 305,37 & 285,78 & 6,52 & 6,3 \\
\hline
\end{tabular}

Fonte: MEC/Inep.

\begin{tabular}{|l|l|l|l|}
\hline C. & ISSN: 1984-3151 & www.unibh.br/revistas/exacta/ & Vol. 3 N. ${ }^{\text {2 }}$ (2010) \\
\hline
\end{tabular}


Tabela 9 - Prova Brasil, Saeb e Ideb calculados para o Ensino Fundamental (Séries Finais), para a Região Sudeste, 2007

\begin{tabular}{|c|c|c|c|c|c|c|c|}
\hline \multirow{2}{*}{$\begin{array}{l}\text { Região/ } \\
\text { Unidade da } \\
\text { Federação }\end{array}$} & \multirow[b]{2}{*}{ Rede } & \multicolumn{2}{|c|}{ Taxa de Aprovação -2007 } & \multicolumn{3}{|c|}{ Nota Prova Brasil/SAEB - 2007} & \multirow{2}{*}{$\begin{array}{c}\text { IDEB } \\
2007 \\
(\mathrm{~N} \times \mathrm{P})\end{array}$} \\
\hline & & $5^{\mathrm{a}}$ a $8^{\mathrm{a}}$ & $\begin{array}{c}\text { Indicador de } \\
\text { Rendimento } \\
\text { (P) }\end{array}$ & Matemática & $\begin{array}{c}\text { Língua } \\
\text { Portuguesa }\end{array}$ & $\begin{array}{c}\text { Nota Média } \\
\text { Padronizada } \\
(\mathrm{N})\end{array}$ & \\
\hline Sudeste & Total & 84,8 & 0,85 & 252,86 & 239,61 & 4,87 & 4,1 \\
\hline Sudeste & Estadual & 83,1 & 0,83 & 244,57 & 232,69 & 4,62 & 3,8 \\
\hline Sudeste & Privada & 95,7 & 0,96 & 301,84 & 279,85 & 6,36 & 6,1 \\
\hline Minas Gerais & Total & 79,5 & 0,79 & 258,31 & 241,85 & 5,00 & 4,0 \\
\hline Minas Gerais & Estadual & 77,5 & 0,77 & 252,89 & 237,30 & 4,84 & 3,7 \\
\hline Minas Gerais & Privada & 94,6 & 0,95 & 318,5 & 290,52 & 6,82 & 6,4 \\
\hline Espírito Santo & Total & 81,5 & 0,82 & 254,21 & 238,58 & 4,88 & 4,0 \\
\hline Espírito Santo & Estadual & 79,8 & 0,80 & 243,82 & 229,69 & 4,56 & 3,6 \\
\hline Espírito Santo & Privada & 95,3 & 0,95 & 304,87 & 280,03 & 6,42 & 6,1 \\
\hline Rio de Janeiro & Total & 78,8 & 0,79 & 248,01 & 238,50 & 4,78 & 3,8 \\
\hline Rio de Janeiro & Estadual & 68,3 & 0,68 & 231,54 & 223,68 & 4,25 & 2,9 \\
\hline Rio de Janeiro & Privada & 92,4 & 0,92 & 284,83 & 269,42 & 5,90 & 5,5 \\
\hline São Paulo & Total & 90,0 & 0,90 & 251,60 & 238,99 & 4,84 & 4,3 \\
\hline São Paulo & Estadual & 88,8 & 0,89 & 242,51 & 231,86 & 4,57 & 4,0 \\
\hline São Paulo & Privada & 97,1 & 0,97 & 304,04 & 281,2 & 6,42 & 6,2 \\
\hline
\end{tabular}

Fonte: MEC/Inep.

Tabela 10 - Prova Brasil, Saeb e Ideb calculados para o Ensino Fundamental (Séries Finais), para a Região Sudeste, 2009

\begin{tabular}{|c|c|c|c|c|c|c|c|}
\hline \multirow{2}{*}{$\begin{array}{l}\text { Região/ } \\
\text { Unidade da } \\
\text { Federação }\end{array}$} & \multirow[b]{2}{*}{ Rede } & \multicolumn{2}{|c|}{ Taxa de Aprovação -2009 } & \multicolumn{3}{|c|}{ Nota Prova Brasil/SAEB - 2009} & \multirow{2}{*}{$\begin{array}{c}\text { IDEB } \\
2009 \\
(\mathrm{~N} \times \mathrm{P})\end{array}$} \\
\hline & & $5^{\mathrm{a}}$ a $8^{\mathrm{a}}$ & $\begin{array}{l}\text { Indicador de } \\
\text { Rendimento } \\
\text { (P) }\end{array}$ & Matemática & $\begin{array}{c}\text { Língua } \\
\text { Portuguesa }\end{array}$ & $\begin{array}{c}\text { Nota Média } \\
\text { Padronizada } \\
\text { (N) }\end{array}$ & \\
\hline Sudeste & Total & 85,5 & 0,85 & 254,53 & 248,96 & 5,06 & 4,3 \\
\hline Sudeste & Estadual & 84,9 & 0,85 & 246,62 & 242,69 & 4,82 & 4,1 \\
\hline Sudeste & Privada & 95,0 & 0,95 & 298,94 & 283,06 & 6,37 & 6,0 \\
\hline Minas Gerais & Total & 81,7 & 0,82 & 264,18 & 254,62 & 5,31 & 4,3 \\
\hline Minas Gerais & Estadual & 80,0 & 0,80 & 258,82 & 251,17 & 5,17 & 4,1 \\
\hline Minas Gerais & Privada & 94,1 & 0,94 & 326,07 & 298,30 & 7,07 & 6,7 \\
\hline Espírito Santo & Total & 79,8 & 0,80 & 257,07 & 250,16 & 5,12 & 4,1 \\
\hline Espírito Santo & Estadual & 79,1 & 0,79 & 246,37 & 240,63 & 4,78 & 3,8 \\
\hline Espírito Santo & Privada & 94,3 & 0,94 & 306,51 & 287,39 & 6,57 & 6,2 \\
\hline Rio de Janeiro & Total & 74,5 & 0,75 & 254,67 & 249,76 & 5,07 & 3,8 \\
\hline Rio de Janeiro & Estadual & 67,2 & 0,67 & 238,54 & 235,81 & 4,57 & 3,1 \\
\hline Rio de Janeiro & Privada & 91,8 & 0,92 & 294,23 & 278,26 & 6,21 & 5,7 \\
\hline São Paulo & Total & 91,7 & 0,92 & 250,22 & 246,26 & 4,94 & 4,5 \\
\hline São Paulo & Estadual & 90,9 & 0,91 & 242,75 & 240,27 & 4,72 & 4,3 \\
\hline São Paulo & Privada & 96,6 & 0,97 & 292,60 & 280,59 & 6,22 & 6,0 \\
\hline
\end{tabular}

Fonte: MEC/Inep.

\begin{tabular}{|l|l|l|l|}
\hline Con & ISSN: 1984-3151 & www.unibh.br/revistas/exacta/ & Vol. 3 N. ${ }^{\text {2 }}$ (2010) \\
\hline
\end{tabular}


Tabela 11 - Prova Brasil, Saeb e Ideb calculados para o Ensino Médio, para a Região Sudeste, 2005

\begin{tabular}{|c|c|c|c|c|c|c|c|c|c|c|c|}
\hline \multirow[b]{2}{*}{$\begin{array}{l}\text { Região/ } \\
\text { Unidade da } \\
\text { Federação }\end{array}$} & \multirow[b]{2}{*}{ Rede } & \multicolumn{6}{|c|}{ Taxa de Aprovação -2005 } & \multicolumn{3}{|c|}{ Nota SAEB - 2005} & \multirow[b]{2}{*}{$\begin{array}{c}\text { IDEB } \\
2005 \\
(\mathrm{~N} \times \mathrm{P})\end{array}$} \\
\hline & & Total & $1^{a}$ & $2^{\mathrm{a}}$ & $3^{\mathrm{a}}$ & $4^{\mathrm{a}}$ & $\begin{array}{l}\text { Indicador de } \\
\text { Rendimento } \\
\text { (P) }\end{array}$ & Matemática & $\begin{array}{c}\text { Língua } \\
\text { Portuguesa }\end{array}$ & $\begin{array}{c}\text { Nota Média } \\
\text { Padronizada } \\
\text { (N) }\end{array}$ & \\
\hline $\begin{array}{l}\text { Sudeste } \\
\text { S }\end{array}$ & Total & 76,1 & 69,1 & 77,3 & 83,6 & 90,0 & 0,79 & 276,74 & 262,70 & 4,51 & 3,6 \\
\hline Sudeste & Estadual & 73,2 & 66,1 & 74,6 & 81,2 & 89,8 & 0,77 & 264,58 & 253,50 & 4,20 & 3,2 \\
\hline Sudeste & Privada & 93,6 & 90,1 & 94,1 & 96,8 & 92,5 & 0,93 & 339,57 & 310,43 & 6,11 & 5,7 \\
\hline Minas Gerais & Total & 73,7 & 66,8 & 76,2 & 80,8 & 96,1 & 0,79 & 290,38 & 268,71 & 4,79 & 3,8 \\
\hline Minas Gerais & Estadual & 71,0 & 64,1 & 73,7 & 78,4 & 95,3 & 0,76 & 279,45 & 260,61 & 4,52 & 3,4 \\
\hline Minas Gerais & Privada & 92,7 & 89,2 & 93,4 & 95,7 & 98,9 & 0,94 & 359,70 & 320,90 & 6,55 & 6,2 \\
\hline Espírito Santo & Total & 75,1 & 67,8 & 76,8 & 83,8 & 100,0 & 0,80 & 282,39 & 267,72 & 4,66 & 3,8 \\
\hline Espírito Santo & Estadual & 70,8 & 63,3 & 72,9 & 80,1 & - & 0,71 & 269,08 & 257,58 & 4,32 & 3,1 \\
\hline Espírito Santo & Privada & 94,6 & 90,9 & 94,4 & 98,5 & 100,0 & 0,96 & 332,61 & 305,96 & 5,94 & 5,7 \\
\hline Rio de Janeiro & Total & 71,1 & 62,5 & 72,5 & 82,2 & 91,7 & 0,76 & 268,91 & 257,03 & 4,31 & 3,3 \\
\hline Rio de Janeiro & Estadual & 67,2 & 58,4 & 68,7 & 79,0 & 92,1 & 0,72 & 251,10 & 241,73 & 3,83 & 2,8 \\
\hline Rio de Janeiro & Privada & 90,3 & 86,3 & 91,1 & 94,4 & 76,2 & 0,86 & 329,24 & 309,18 & 5,94 & 5,1 \\
\hline São Paulo & Total & 79,2 & 73,4 & 79,8 & 85,4 & 87,4 & 0,81 & 272,92 & 261,57 & 4,44 & 3,6 \\
\hline São Paulo & Estadual & 76,7 & 70,7 & 77,3 & 83,2 & 86,5 & 0,79 & 261,81 & 253,64 & 4,16 & 3,3 \\
\hline São Paulo & Privada & 95,3 & 92,2 & 95,6 & 98,1 & 97,9 & 0,96 & 337,16 & 307,37 & 6,03 & 5,8 \\
\hline
\end{tabular}

Tabela 12 - Prova Brasil, Saeb e Ideb calculados para o Ensino Médio, para a Região Sudeste, 2007

\begin{tabular}{|c|c|c|c|c|c|c|c|c|c|c|c|}
\hline \multirow[b]{2}{*}{$\begin{array}{l}\text { Região/ } \\
\text { Unidade da } \\
\text { Federação }\end{array}$} & \multirow[b]{2}{*}{ Rede } & \multicolumn{6}{|c|}{ Taxa de Aprovação -2007 } & \multicolumn{3}{|c|}{ Nota Prova Brasil/SAEB - 2007} & \multirow[b]{2}{*}{$\begin{array}{l}\text { IDEB } \\
2007 \\
(\mathrm{~N} \times \mathrm{P})\end{array}$} \\
\hline & & Total & $1^{a}$ & $2^{\mathrm{a}}$ & $3^{\mathrm{a}}$ & $4^{a}$ & $\begin{array}{c}\text { Indicador de } \\
\text { Rendimento } \\
(\mathrm{P})\end{array}$ & Matemática & \begin{tabular}{|c|} 
Língua \\
Portuguesa
\end{tabular} & $\begin{array}{c}\text { Nota Média } \\
\text { Padronizada } \\
(\mathrm{N})\end{array}$ & \\
\hline Sudeste & Total & 76,3 & 70,3 & 77,9 & 83,1 & 90,7 & 0,80 & 280,42 & 268,94 & 4,65 & 3,7 \\
\hline Sudeste & Estadual & 73,8 & 67,8 & 75,5 & 80,7 & 90,9 & 0,78 & 269,22 & 260,61 & 4,37 & 3,4 \\
\hline Sudeste & Privada & 94,4 & 91,0 & 95,0 & 97,5 & 91,2 & 0,94 & 338,82 & 312,20 & 6,12 & 5,7 \\
\hline Minas Gerais & Total & 75,6 & 70,5 & 77,6 & 80,8 & 82,5 & 0,78 & 289,35 & 276,71 & 4,90 & 3,8 \\
\hline Minas Gerais & Estadual & 73,6 & 68,7 & 75,7 & 78,7 & 81,8 & 0,76 & 279,81 & 270,17 & 4,66 & 3,5 \\
\hline Minas Gerais & Privada & 92,9 & 89,6 & 94,0 & 95,9 & 84,2 & 0,91 & 348,00 & 317,93 & 6,34 & 5,7 \\
\hline Espírito Santo & Total & 77,2 & 70,9 & 78,8 & 84,4 & 86,1 & 0,80 & 277,45 & 261,67 & 4,50 & 3,6 \\
\hline Espírito Santo & Estadual & 73,8 & 67,7 & 75,6 & 81,2 & 84,6 & 0,77 & 262,09 & 249,64 & 4,11 & 3,2 \\
\hline Espírito Santo & Privada & 94,3 & 89,9 & 94,4 & 98,5 & 96,2 & 0,95 & 342,69 & 312,64 & 6,18 & 5,9 \\
\hline Rio de Janeiro & Total & 67,3 & 57,4 & 68,8 & 79,7 & 91,6 & 0,72 & 271,87 & 260,51 & 4,41 & 3,2 \\
\hline Rio de Janeiro & Estadual & 64,0 & 54,0 & 65,4 & 77,1 & 91,8 & 0,69 & 255,27 & 246,84 & 3,97 & 2,8 \\
\hline Rio de Janeiro & Privada & 90,1 & 85,1 & 90,4 & 95,7 & 92,3 & 0,91 & 331,30 & 309,87 & 5,98 & 5,4 \\
\hline São Paulo & Total & 79,8 & 74,9 & 81,2 & 85,3 & 92,8 & 0,83 & 279,43 & 268,77 & 4,64 & 3,9 \\
\hline São Paulo & Estadual & 77,2 & 72,3 & 78,8 & 82,9 & - & 0,78 & 269,36 & 261,44 & 4,39 & 3,4 \\
\hline São Paulo & Privada & 96,0 & 93,3 & 96,6 & 98,6 & 93,5 & 0,95 & 337,98 & 310,86 & 6,09 & 5,8 \\
\hline
\end{tabular}

Fonte: MEC/Inep.

Tabela 13 - Prova Brasil, Saeb e Ideb calculados para o Ensino Médio, para a Região Sudeste, 2009

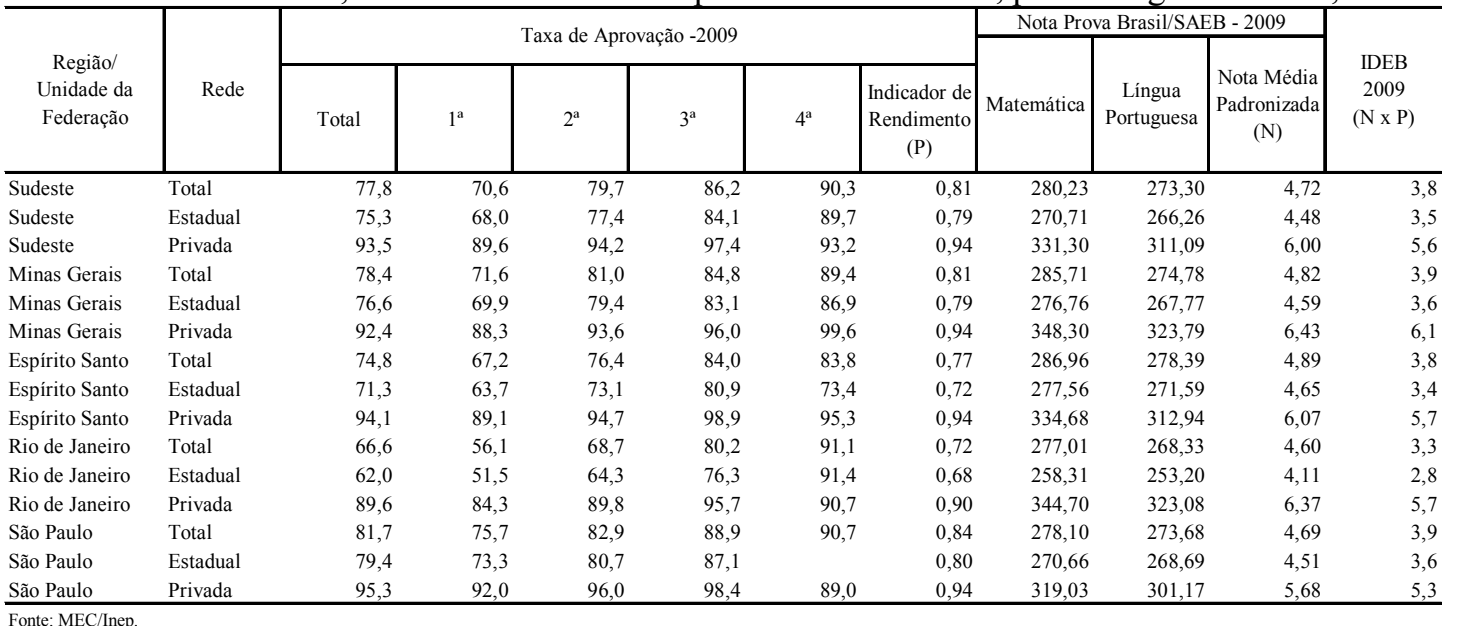

\begin{tabular}{|l|l|l|l|}
\hline C. & ISSN: 1984-3151 & www.unibh.br/revistas/exacta/ & Vol. 3 N. ${ }^{\circ} 2(2010)$ \\
\hline
\end{tabular}


Tabela 14 - Projeções do Ideb calculadas para o Ensino Fundamental (Séries Iniciais), referentes à

\begin{tabular}{|c|c|c|c|c|c|c|c|c|c|}
\hline \multirow{2}{*}{$\begin{array}{c}\text { Região/ } \\
\text { Unidade da Federação }\end{array}$} & \multirow{2}{*}{ Rede } & \multicolumn{8}{|c|}{ Projeções } \\
\hline & & 2007 & 2009 & 2011 & 2013 & 2015 & 2017 & 2019 & 2021 \\
\hline Sudeste & Estadual & 4,6 & 4,9 & 5,3 & 5,6 & 5,8 & 6,1 & 6,3 & 6,6 \\
\hline Sudeste & Privada & 6,3 & 6,6 & 6,9 & 7,1 & 7,3 & 7,4 & 7,6 & 7,8 \\
\hline Minas Gerais & Privada & 7,0 & 7,2 & 7,4 & 7,6 & 7,7 & 7,9 & 8,0 & 8,1 \\
\hline Espírito Santo & Total & 4,3 & 4,6 & 5,0 & 5,3 & 5,6 & 5,8 & 6,1 & 6,3 \\
\hline Espírito Santo & Estadual & 3,8 & 4,1 & 4,5 & 4,8 & 5,1 & 5,4 & 5,7 & 5,9 \\
\hline Espírito Santo & Privada & 6,4 & 6,6 & 6,9 & 7,1 & 7,3 & 7,5 & 7,6 & 7,8 \\
\hline Rio de Janeiro & Total & 4,4 & 4,7 & 5,1 & 5,4 & 5,6 & 5,9 & 6,1 & 6,4 \\
\hline São Paulo & Privada & 6,6 & 6,8 & 7,1 & 7,3 & 7,5 & 7,6 & 7,8 & 7,9 \\
\hline
\end{tabular}

Tabela 15 - Projeções do Ideb calculadas para o Ensino Fundamental (Séries Finais), referentes à Região Sudeste

\begin{tabular}{|c|c|c|c|c|c|c|c|c|c|}
\hline \multirow{2}{*}{$\begin{array}{c}\text { Região/ } \\
\text { Unidade da Federação }\end{array}$} & \multirow{2}{*}{ Rede } & \multicolumn{8}{|c|}{ Projeções } \\
\hline & & 2007 & 2009 & 2011 & 2013 & 2015 & 2017 & 2019 & 2021 \\
\hline Sudeste & Total & 4,0 & 4,1 & 4,4 & 4,8 & 5,2 & 5,4 & 5,7 & 5,9 \\
\hline Sudeste & Estadual & 3,7 & 3,8 & 4,1 & 4,5 & 4,9 & 5,1 & 5,4 & 5,6 \\
\hline Sudeste & Privada & 6,1 & 6,2 & 6,5 & 6,8 & 7,0 & 7,2 & 7,4 & 7,5 \\
\hline Minas Gerais & Total & 3,8 & 3,9 & 4,2 & 4,6 & 5,0 & 5,2 & 5,5 & 5,7 \\
\hline Minas Gerais & Estadual & 3,6 & 3,8 & 4,0 & 4,4 & 4,8 & 5,1 & 5,3 & 5,6 \\
\hline Minas Gerais & Privada & 6,5 & 6,6 & 6,8 & 7,0 & 7,3 & 7,4 & 7,6 & 7,7 \\
\hline Espírito Santo & Total & 3,8 & 4,0 & 4,3 & 4,7 & 5,0 & 5,3 & 5,5 & 5,8 \\
\hline Espírito Santo & Estadual & 3,6 & 3,7 & 4,0 & 4,4 & 4,8 & 5,0 & 5,3 & 5,5 \\
\hline Espírito Santo & Privada & 6,0 & 6,1 & 6,3 & 6,6 & 6,9 & 7,1 & 7,2 & 7,4 \\
\hline Rio de Janeiro & Total & 3,6 & 3,8 & 4,1 & 4,5 & 4,9 & 5,1 & 5,4 & 5,6 \\
\hline Rio de Janeiro & Estadual & 2,9 & 3,1 & 3,3 & 3,7 & 4,1 & 4,4 & 4,6 & 4,9 \\
\hline Rio de Janeiro & Privada & 5,5 & 5,6 & 5,9 & 6,2 & 6,5 & 6,7 & 6,9 & 7,1 \\
\hline São Paulo & Total & 4,2 & 4,4 & 4,6 & 5,0 & 5,4 & 5,6 & 5,9 & 6,1 \\
\hline São Paulo & Estadual & 3,8 & 4,0 & 4,2 & 4,6 & 5,0 & 5,3 & 5,5 & 5,8 \\
\hline São Paulo & Privada & 6,3 & 6,5 & 6,7 & 6,9 & 7,2 & 7,4 & 7,5 & 7,7 \\
\hline
\end{tabular}

Tabela 16 - Projeções do Ideb calculadas para o Ensino Médio, referentes à Região Sudeste

\begin{tabular}{|c|c|c|c|c|c|c|c|c|c|}
\hline \multirow{2}{*}{$\begin{array}{c}\text { Região/ } \\
\text { Unidade da Federação }\end{array}$} & \multirow{2}{*}{ Rede } & \multicolumn{8}{|c|}{ Projeções } \\
\hline & & 2007 & 2009 & 2011 & 2013 & 2015 & 2017 & 2019 & 2021 \\
\hline Sudeste & Total & 3,6 & 3,7 & 3,9 & 4,1 & 4,5 & 4,9 & 5,2 & 5,4 \\
\hline Sudeste & Estadual & 3,3 & 3,3 & 3,5 & 3,8 & 4,1 & 4,6 & 4,8 & 5,1 \\
\hline Sudeste & Privada & 5,7 & 5,8 & 6,0 & 6,2 & 6,4 & 6,8 & 6,9 & 7,1 \\
\hline Minas Gerais & Total & 3,8 & 3,9 & 4,1 & 4,3 & 4,7 & 5,1 & 5,3 & 5,6 \\
\hline Minas Gerais & Estadual & 3,5 & 3,6 & 3,7 & 4,0 & 4,4 & 4,8 & 5,0 & 5,3 \\
\hline Minas Gerais & Privada & 6,2 & 6,3 & 6,4 & 6,6 & 6,8 & 7,1 & 7,3 & 7,4 \\
\hline Espírito Santo & Total & 3,8 & 3,9 & 4,1 & 4,3 & 4,7 & 5,1 & 5,3 & 5,6 \\
\hline Espírito Santo & Estadual & 3,1 & 3,2 & 3,4 & 3,6 & 4,0 & 4,4 & 4,7 & 4,9 \\
\hline Espírito Santo & Privada & 5,7 & 5,8 & 5,9 & 6,2 & 6,4 & 6,8 & 6,9 & 7,1 \\
\hline Rio de Janeiro & Total & 3,3 & 3,4 & 3,6 & 3,8 & 4,2 & 4,6 & 4,9 & 5,1 \\
\hline Rio de Janeiro & Estadual & 2,8 & 2,9 & 3,1 & 3,3 & 3,7 & 4,1 & 4,4 & 4,6 \\
\hline Rio de Janeiro & Privada & 5,2 & 5,2 & 5,4 & 5,6 & 6,0 & 6,3 & 6,5 & 6,7 \\
\hline São Paulo & Total & 3,6 & 3,7 & 3,9 & 4,2 & 4,5 & 5,0 & 5,2 & 5,4 \\
\hline São Paulo & Estadual & 3,3 & 3,4 & 3,6 & 3,9 & 4,2 & 4,6 & 4,9 & 5,1 \\
\hline São Paulo & Privada & 5,8 & 5,9 & 6,0 & 6,2 & 6,5 & 6,8 & 7,0 & 7,2 \\
\hline
\end{tabular}

Fonte: MEC/Inep.

\begin{tabular}{|l|l|l|} 
ISSN: 1984-3151 & www.unibh.br/revistas/exacta/ & Vol. 3 N. ${ }^{\circ} 2(2010)$ \\
\hline
\end{tabular}

